\title{
Improved flexibility and economics of Calcium Looping power plants by thermochemical energy storage
}

\author{
Marco Astolfi, Edoardo De Lena, Matteo C. Romano* \\ Politecnico di Milano, Department of Energy, via Lambruschini 4, 20156, Milano, Italy
}

\section{A R T I C L E I N F O}

\section{Keywords:}

Energy storage

CCS

$\mathrm{CO}_{2}$ capture

Part-load

\begin{abstract}
A B S T R A C T
In this work, a Calcium looping (CaL) system including high temperature sorbent storage is presented, allowing to reduce the size of the calciner and the associated capital-intensive equipment (ASU and CPU). Reduction of the capital costs is particularly important for power plants with low capacity factors, which is becoming increasingly frequent for fossil fuel power plants in electric energy mixes with increasing share of intermittent renewables. The process assessment is performed by: (i) defining pulverized coal power plant (PCPP) with CaL capture system with and without sorbent storage and their mass and energy balances at nominal load; (ii) defining a simple method to predict the performance of the plant at part-load; (iii) defining the economic model, including functions for the estimation of the plant equipment cost; (iv) performing yearly simulations of the systems to calculate yearly electricity production, $\mathrm{CO}_{2}$ emissions and levelized cost of electricity for different sizes of the calcination line and the storage system and (v) performing sensitivity analysis with different power production plans and carbon taxes. With this process, optimal size of the calciner and of the storage system minimizing the cost of electricity have been found.

The optimal plant design was found to correspond to a solids storage system sized to manage the weekly cycling and a calciner line sized on the average weekly load. However, to avoid excessively large solids storage system, sizing the calciner on the average daily load and the storage system to manage the daily cycling appears more feasible from the logistic viewpoint and leads to minor economic penalty compared with the optimal plant design. For the selected case sized on the daily cycling, reduction of the cost of $\mathrm{CO}_{2}$ avoided between $16 \%$ and $26 \%$ have been obtained compared to the reference CaL plant without solids storage, for representative medium and low capacity factor scenarios respectively.
\end{abstract}

\section{Introduction}

Calcium looping (CaL) is one of the emerging technologies for $\mathrm{CO}_{2}$ capture with the quickest development in the last two decades (Abanades et al., 2015). After the first formulation of the concept 20 years ago (Shimizu et al., 1999) and significant fundamental research on sorbent properties, reactors design and operation, process integration and economic analyses (Blamey et al., 2010; Dean et al., 2011; Martínez et al., 2016; Perejón et al., 2016), the technology has been demonstrated in two different facilities of 1-1.7 $\mathrm{MW}_{\text {th }}$ scale (Arias et al., 2013; Kremer et al., 2013; Ströhle et al., 2014). While waiting for conditions favorable for the scale-up of the technology, research on CaL process for post-combustion $\mathrm{CO}_{2}$ capture recently focused on some specific topics, such as the operation of the calciner with high $\mathrm{O}_{2}$ concentration to reduce fuel consumption and equipment size (Arias et al., 2018), the adoption of indirectly heated calcination to avoid the air separation unit (Martínez et al., 2016, 2011; Reitz et al., 2016), the design of advanced configurations to transfer heat from the hot calcined solids to the colder carbonated sorbent (Martínez et al., 2012; Vorrias et al., 2013), techniques for improving the sorbent capacity by reactivation (Diego et al., 2016), the integration with renewables by solar assisted calcination (Matthews and Lipiński, 2012), the assessment and design of the process for application in cement plants (Arias et al., 2017; De Lena et al., 2017; Hornberger et al., 2017; Spinelli et al., 2018). Another research field on CaL for power plants which is attracting increasing interest is the exploitation of the calcined sorbent $(\mathrm{CaO})$ as thermochemical energy storage medium, to improve the flexibility and reduce the cost of electricity of power plants in energy mixes with increasing share of intermittent renewable energy sources (Criado et al., 2017; Hanak et al., 2016). This paper, which derives from the research carried out in the RFCS project FlexiCaL (FlexiCaL, 2016), focuses on this last topic.

\footnotetext{
* Corresponding author.

E-mail address: matteo.romano@polimi.it (M.C. Romano).
} 


\begin{tabular}{ll} 
Nomenclature \\
Acronyms & \\
& \\
BOP & Balance of plant \\
CaL & Calcium looping \\
CaLPP & Calcium looping power plant \\
Capex & Capital expenditure \\
CCA & ${\text { Cost of } \mathrm{CO}_{2} \text { avoided }}_{\text {CCE }}$ CO $_{2}$ capture efficiency \\
CF & Capacity factor \\
CFB & Circulating fluidized bed \\
CPU & CO 2 purification unit \\
CT & Carbon tax \\
EHE & External heat exchanger \\
FGD & Flue gas desulfurizer \\
FWH & Feed water heater \\
HHV & Higher heating value \\
LCOE & Levelized cost of electricity \\
LHV & Lower heating value \\
LT & Low temperature \\
MT & Medium temperature \\
O\&M & Operating and maintenance \\
Opex & Operating expenditure \\
PC & Pulverized coal \\
PCPP & Pulverized coal power plant \\
RFCS & Research Fund for Coal and Steel \\
SPECCA & Specific primary energy consumption for $\mathrm{CO}_{2}$ avoided \\
TASC & Total as-spent cost \\
TPC & Total plant cost \\
USC & Ultra supercritical \\
& \\
\hline
\end{tabular}

The fundamental motivation for this work can be understood by analyzing the yearly thermodynamic (Table 1) and economic (Table 2) indicators of a conventional CaL power plant compared to a conventional Pulverized Coal Power Plant (PCPP). The methodology adopted to obtain the reference values in Tables 1 and 2 is presented in the following sections on the paper, but values can be considered indicative for a CaL power plant designed for base-load power generation (Martínez et al., 2016) and help supporting this discussion which has a general validity. In coal-fired power plants, Capex represent the main contribution to the cost of electricity. This is amplified in power plants with $\mathrm{CO}_{2}$ capture because of the additional cost of the equipment required for $\mathrm{CO}_{2}$ separation and compression and because of the reduction of electric efficiency, which causes an increase of the specific capital cost per unit nominal power output $\left(€ / \mathrm{kW}_{\text {nom }}\right)$ of conventional components. In the CaL example in Tables 1 and 2, designed with both reactors on the nominal size of the PCPP, about $45 \%$ of the levelized cost of electricity (LCOE) can be attributed to Capex.

When the capacity factor of power plants is reduced, which may occur in electric systems with high penetration of intermittent renewable energy sources, the cost of electricity increases, especially for capital intensive power plants. This is shown for example in Fig. 1, by comparing the LCOE of the benchmark PCPP and the reference PCPP + CaL power plants as function of the capacity factor and of the carbon tax (CT). For base-load power plants ( $\mathrm{CF}=90 \%$ ), a CT slightly higher than $30 € / \mathrm{t}_{\mathrm{CO} 2}$ would be sufficient to make the CaL power plant competitive with the reference pulverized coal power plant (PCPP). If the $\mathrm{CF}$ reduces to $50 \%$, the breakeven CT increases to about $45 € / \mathrm{t}_{\mathrm{CO} 2}$ and a further reduction of the $\mathrm{CF}$ to $30 \%$ would require a CT higher than $60 € / \mathrm{t}_{\mathrm{CO} 2}$ to make the CaL power plant economically competitive. Therefore, one of the primary drivers to improve the economic competitiveness of $\mathrm{CaL}$ power plants (and of other $\mathrm{CO}_{2}$ capture technologies) in energy mixes dominated by renewables and with reduced $\mathrm{CF}$ for

\section{Symbols}

\section{Cost}

CAPEX $_{a}$ Annualized capital cost [€/year]

$C C F \quad$ Capital charge factor [1/year]

$E E_{\text {net }} \quad$ Yearly net electric energy production [MWh/year]

$f \quad$ Scaling law exponent

$F_{0} \quad$ Limestone make up $\left[\mathrm{kmol}_{\mathrm{Ca}} / \mathrm{s}\right]$

$F_{C a} \quad$ Sorbent circulation rate $\left[\mathrm{kmol}_{\mathrm{Ca}} / \mathrm{s}\right]$

$\mathrm{F}_{\mathrm{CO} 2} \quad \mathrm{CO}_{2}$ flow rate at carbonator inlet $\left[\mathrm{kmol}_{\mathrm{CO} 2} / \mathrm{s}\right]$

$L \quad$ Load

$L R \quad$ Calciner to carbonator load ratio

$\dot{Q} \quad$ Thermal power

$S \quad$ Size

$\dot{W} \quad$ Electric power

$X_{\text {carb }} \quad$ Sorbent carbonation degree $\left[\mathrm{kmol}_{\mathrm{CaCO} 3} / \mathrm{kmol}_{\mathrm{Ca}}\right]$

\section{Subscripts and superscripts}

$\begin{array}{ll}\text { aux } & \text { auxiliaries } \\ \text { calc } & \text { calciner } \\ \text { carb } & \text { carbonator } \\ \text { e } & \text { electric } \\ \text { fg } & \text { flue gas } \\ \text { nom } & \text { nominal } \\ \text { off } & \text { off design } \\ \text { ref } & \text { reference } \\ \text { T\&S } & \mathrm{CO}_{2} \text { transport and storage } \\ \text { th } & \text { thermal } \\ \text { var } & \text { variable } \\ \text { vol } & \text { volume }\end{array}$

fossil fuel power plants is to reduce the Capex of the $\mathrm{CO}_{2}$ capture plant, while keeping high energy efficiency and achieve in this way low specific Capex $\left(€ / \mathrm{kW}_{\text {nom }}\right)$.

A significant share of the Capex of a CaL system (about 30\%, estimated with the economic model presented in the next sections) is associated to the calciner line, composed by the calciner, the $\mathrm{CO}_{2}$-rich gas convective pass, the air separation unit (ASU), the $\mathrm{CO}_{2}$ compression and purification unit (CPU), the portion of steam cycle and the devices for coal, sorbent and ash handling associated to the heat recovered and the fuel consumed in the calciner line. So, the idea assessed in this paper,

Table 1

Representative yearly energy indicators of base-load pulverized coal power plant (PCPP) without $\mathrm{CO}_{2}$ capture and with $\mathrm{CO}_{2}$ capture by $\mathrm{CaL}$ process (PCPP + CaL). Capacity factor equal to 0.9 .

\begin{tabular}{|c|c|c|}
\hline & PCPP & Reference PCPP + CaL \\
\hline \multicolumn{3}{|l|}{ Nominal data } \\
\hline Nominal net power output, MW & 747.2 & 1138.2 \\
\hline Nominal gross power output, MW & 804.8 & 1440.9 \\
\hline Nominal fuel input, $\mathrm{MW}_{\mathrm{LHV}}$ & 1676.5 & 3033.7 \\
\hline Nominal net electric efficiency, $\%$ & $44.57 \%$ & $37.52 \%$ \\
\hline Nominal $\mathrm{CO}_{2}$ emission, $\mathrm{kg} / \mathrm{s}$ & 162.65 & 25.01 \\
\hline Nominal $\mathrm{CO}_{2}$ emission, $\mathrm{kg} / \mathrm{MWh}$ & 782.7 & 79.1 \\
\hline Nominal Stored $\mathrm{CO}_{2}, \mathrm{~kg} / \mathrm{s}$ & - & 283.6 \\
\hline Coal consumption, $\mathrm{kg} / \mathrm{s}$ & 66.61 & 120.53 \\
\hline $\mathrm{CaCO}_{3}$ consumption, $\mathrm{kg} / \mathrm{s}$ & 1.01 & 37.00 \\
\hline \multicolumn{3}{|l|}{ Annual results } \\
\hline Annual net energy output, GWh/year & 5891 & 8973 \\
\hline Annual gross energy output,GWh/year & 6345 & 11360 \\
\hline Annual $\mathrm{CO}_{2}$ emission, $\mathrm{Mt} /$ year & 4.616 & 0.710 \\
\hline Annual coal consumption, Mt/year & 1.890 & 3.421 \\
\hline Annual $\mathrm{CaCO}_{3}$ consumption, Mt/year & 0.029 & 1.050 \\
\hline Annual stored $\mathrm{CO}_{2}$, Mt/year & 0.000 & 8.049 \\
\hline
\end{tabular}


Table 2

Representative yearly economic indicators of base-load pulverized coal power plant (PCPP) without $\mathrm{CO}_{2}$ capture and with $\mathrm{CO}_{2}$ capture by $\mathrm{CaL}$ process (PCPP + CaL). Capacity factor equal to 0.9 .

\begin{tabular}{|c|c|c|}
\hline & PCPP & Reference PCPP $+\mathrm{CaL}$ \\
\hline \multicolumn{3}{|l|}{ Cost analysis } \\
\hline Specific cost, $€ / \mathrm{kW}_{\text {nom }}$ & 2011 & 2631 \\
\hline As-spent cost, $\mathrm{M} €$ & 1503 & 2994 \\
\hline Specific fuel cost, $€ / \mathrm{GJ}_{\mathrm{LHV}}$ & 2.58 & 2.58 \\
\hline Fuel Opex, M€/year & 122.88 & 222.35 \\
\hline $\mathrm{CaCO}_{3}$ Opex, $\mathrm{M} € /$ year & 0.43 & 15.75 \\
\hline Other variable Opex, M€/year & 24.30 & 43.51 \\
\hline Fixed Opex, M€/year & 38.77 & 77.25 \\
\hline $\mathrm{CO}_{2}$ transport and storage $\mathrm{M} € /$ year & 0.00 & 56.34 \\
\hline Capex depreciation, M€/year & 165.30 & 329.36 \\
\hline Total annual cost, M€/year & 351.69 & 744.57 \\
\hline \multicolumn{3}{|l|}{ LCOE } \\
\hline Capex, €/MWh & 28.06 & 36.70 \\
\hline Fuel Opex, €/MWh & 20.86 & 24.78 \\
\hline $\mathrm{CaCO}_{3}$ Opex, €/MWh & 0.07 & 1.76 \\
\hline Other variable Opex, €/MWh & 4.13 & 4.85 \\
\hline Fixed Opex, €/MWh & 6.58 & 8.61 \\
\hline $\mathrm{CO}_{2}$ transport and storage $€ / \mathrm{MWh}$ & 0.00 & 6.28 \\
\hline \multicolumn{3}{|l|}{$L C O E$ with carbon $\operatorname{tax} € / t$} \\
\hline LCOE, €/MWh @ 0€/t & 59.70 & 82.98 \\
\hline LCOE, €/MWh @ $30 € / \mathrm{t}$ & 83.21 & 85.35 \\
\hline LCOE, €/MWh @ 60€/t & 106.72 & 87.72 \\
\hline LCOE, €/MWh @ 90€/t & 130.23 & 90.09 \\
\hline $\mathrm{CCA}, € / \mathrm{t}$ & & 33.04 \\
\hline
\end{tabular}

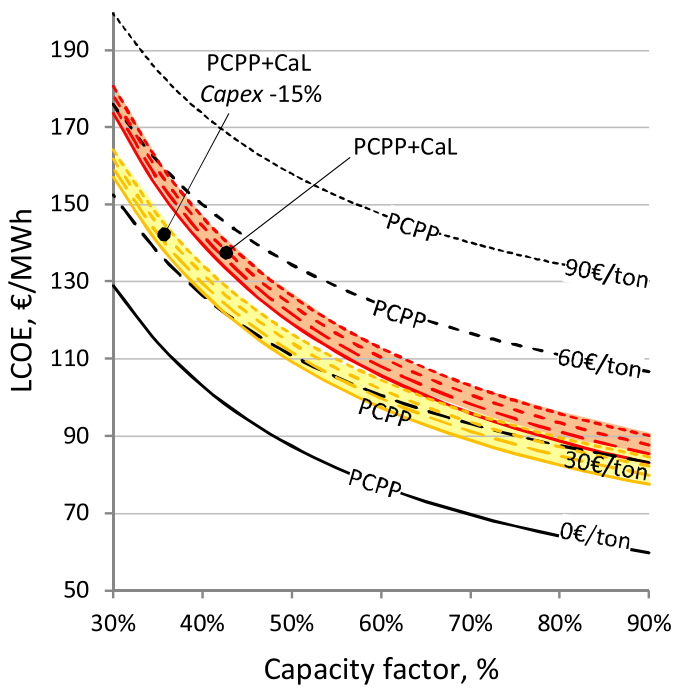

Fig. 1. LCOE for a PCPP without $\mathrm{CO}_{2}$ capture and for a greenfield Calcium Looping system (PCPP $+\mathrm{CaL}$ ) with reference and reduced $(-15 \%)$ Capex, as function of the capacity factor, for four values of the Carbon Tax $(0,30,60,90$ $€ / \mathrm{t})$.

which was originally proposed for oxyfuel (Arias, 2016; Arias et al., 2014) and for CaL power plants (Criado et al., 2017), is to reduce the Capex associated to the oxyfuel calciner line by means of sorbent storage. According to this principle, the calciner line can be sized and operated at the average load of a target period (e.g. daily average), while sorbent storage allows managing the fluctuations associated to the cycling of the PCPP. This can be achieved by storing carbonated sorbent when the PCPP and the carbonator operate at a load higher than the average one and storing calcined sorbent when the PCPP and the carbonator operate at a load lower than the average one. The
Table 3

Coal composition and heating values.

\begin{tabular}{ll}
\hline $\mathrm{C}$ & $66.52 \%$ \\
$\mathrm{~N}$ & $1.56 \%$ \\
$\mathrm{H}$ & $3.78 \%$ \\
$\mathrm{O}$ & $5.46 \%$ \\
$\mathrm{~S}$ & $0.52 \%$ \\
Ash & $14.15 \%$ \\
$\mathrm{Moisture}$ & $8.01 \%$ \\
$\mathrm{LHV}, \mathrm{MJ} / \mathrm{kg}$ & 25.17 \\
$\mathrm{HHV}, \mathrm{MJ} / \mathrm{kg}$ & 26.23 \\
\hline
\end{tabular}

potential benefits for the LCOE of a reduction of the Capex of a CaL power plant is shown again in Fig. 1, for a case where Capex of the PCPP + CaL power plant is reduced by $15 \%$. For this case, the breakeven CT increases much less when the CF reduces from $90 \%$ to $30 \%$, increasing from about 25 to $40 € / \mathrm{t}_{\mathrm{CO} 2}$.

The scope of this work is to perform an economic optimization of a CaL system with thermochemical energy storage and to find the economic optimal size of the storage silos and of the calciner for different carbon taxes and power plant load profiles. Compared with the work previously published on the same topic (Criado et al., 2017), the novelty of this work mainly consists in: (i) performing an economic optimization of the size of the storage silos and of the calciner and (ii) considering a CaL system with operating parameters relevant for daily/ weekly cycling and intermediate CFs (i.e.: storage of solids at temperatures close to CaL reactors one and moderate fresh limestone makeup flow rate) rather than for back-up systems with very low CF (i.e.: storage of solids at moderate temperature of around $250{ }^{\circ} \mathrm{C}$ and consistent limestone make-up flow rates).

\section{Reference PCPP + CaL power plant without solids storage}

The PCPP is based on an air-blown boiler burning low sulfur bituminous coal (Table 3) and an Ultra Supercritical (USC) steam cycle with net power output of 747.2 $\mathrm{MW}_{\mathrm{e}}$ and $44.6 \%_{\mathrm{LHV}}$ of net electric efficiency. The plant generates $743.8 \mathrm{~kg} / \mathrm{s}$ of flue gas with a $\mathrm{CO}_{2}$ concentration of $14.9 \%$ vol, leading to specific emissions of $782.7 \mathrm{~kg}_{\mathrm{CO} 2} / \mathrm{MWh}$.

In Fig. 2, a schematic of the CaL plant for $\mathrm{CO}_{2}$ capture from a conventional PCPP is shown. Flue gas from the PCPP (stream \#1) is compressed by a fan (a), preheated to $300^{\circ} \mathrm{C}$ in a Ljungström gas-gas heater (b) and fed to the carbonator (c), which is a cooled circulating fluidized bed (CFB) reactor. After solids separation in a cyclone (d), carbonator off gas (2) is first cooled to $350{ }^{\circ} \mathrm{C}$ in a convective pass (e) and then in the gas-gas heat exchanger (b) before being emitted at the stack (f).

CaO-rich solids (3) are fed to the bottom of the carbonator and react with the $\mathrm{CO}_{2}$ in the flue gases producing $\mathrm{CaCO}_{3}$ through the exothermic carbonation reaction $\left(\mathrm{CaO}+\mathrm{CO}_{2} \rightarrow \mathrm{CaCO}_{3}\right)$. Thanks to the very high $\mathrm{Ca} / \mathrm{S}$ ratio, sulfur dioxide is also removed with very high efficiency in the carbonator (Alonso et al., 2014; Arias et al., 2013) by reaction with $\mathrm{CaO}$ forming $\mathrm{CaSO}_{4}$. Therefore, gas treated in the carbonator does not need further desulfurization in a wet flue gas desulfurizer (FGD). The use of the carbonator as flue gas desulfurizer leads to savings in the capital (for greenfield plants) and operating costs associated to the wet FGD. On the other hand, sorbent sulfation negatively affects its activity, because the formation of $\mathrm{CaSO}_{4}$ causes the irreversible loss of part of the $\mathrm{CaO}$ active in $\mathrm{CO}_{2}$ capture. This effect is taken into account in the carbonator model used in this work (Romano, 2012), which uses a correlation based on the experimental findings by (Grasa et al., 2008). Due to the low sulfur content of the coal considered in this work, a modest effect of the lack of the FGD has been estimated with the carbonator model: limestone make-up could be reduced by about $10 \%$ if the FGD is installed and operated, avoiding sorbent sulfation by $\mathrm{SO}_{2}$ in 


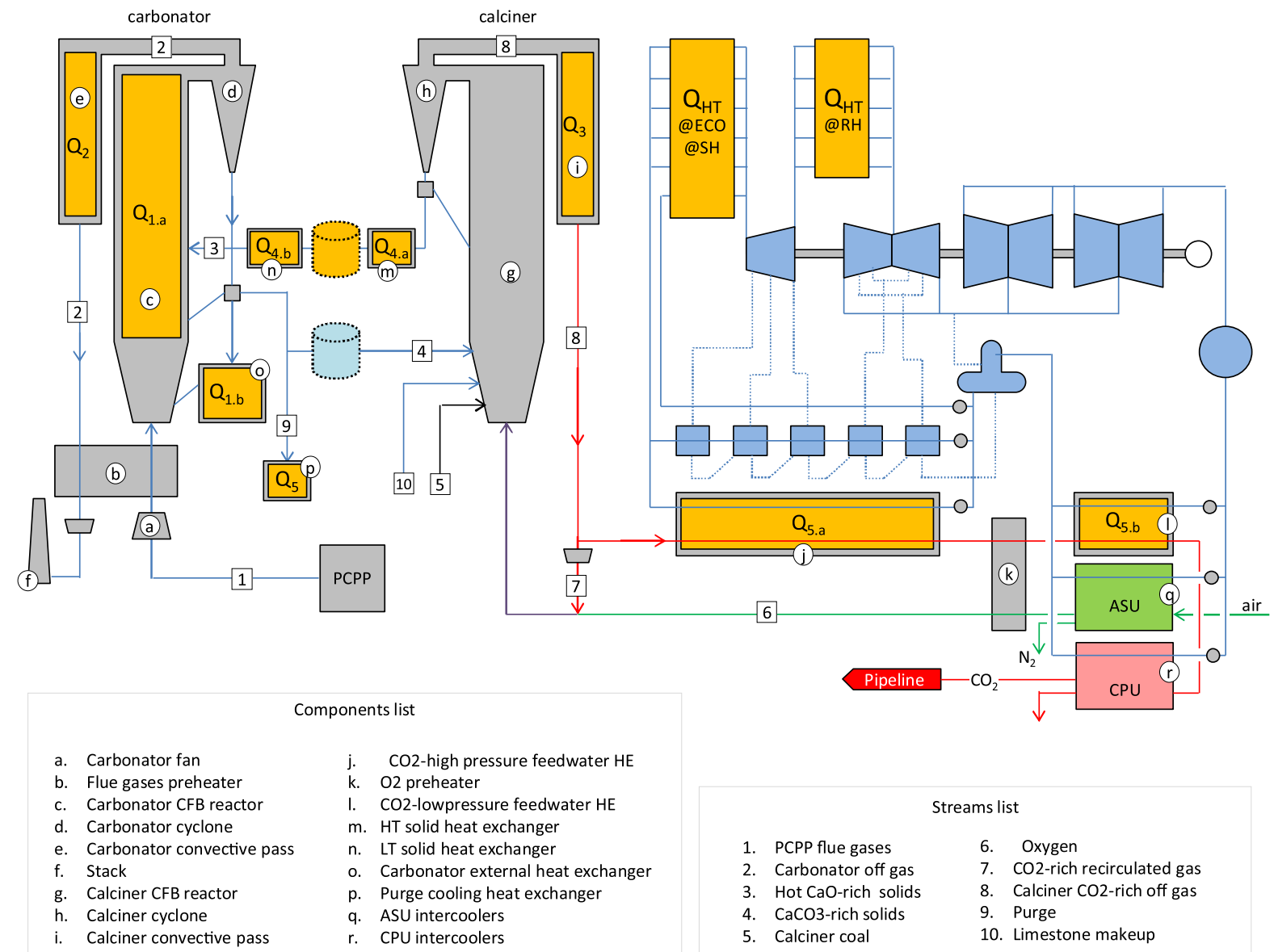

Fig. 2. Calcium looping plant for $\mathrm{CO}_{2}$ capture from a conventional PCPP. Silos for solids storage are drawn with dashed lines and are not present in the reference CaL system.

the PCPP flue gas. From a basic economic estimation on the main items $^{1}$, in the assessed system it appears preferable to avoid the wet FGD and operate the carbonator as desulfurizer. In any case, the modelling approach and the general results of this paper are unaffected by the presence or the absence of the wet FGD.

Carbonated solids (4) are fed to the calciner ( $\mathrm{g}$ ), which is a refractory lined $\mathrm{CFB}$ reactor operating at $920{ }^{\circ} \mathrm{C}$, where $\mathrm{CaCO}_{3}$ is converted back to $\mathrm{CaO}$ releasing a concentrated stream of $\mathrm{CO}_{2}$. Heat for endothermic calcination reaction and for heating the solids to the calcination temperature is provided by the oxy-combustion of coal (5). High purity oxygen (6) for combustion is produced in a cryogenic air separation unit (ASU) and diluted with recirculated gas (7) at $350{ }^{\circ} \mathrm{C}$ to achieve an $\mathrm{O}_{2}$ concentration of $50 \%$ vol at the calciner inlet. Calciner off gas (8) is separated from solids in a cyclone (h) and it is cooled to $350{ }^{\circ} \mathrm{C}$ in a convective pass before gas recycle (i) and to nearly ambient temperature in low temperature heat recovery sections $(\mathrm{j}, \mathrm{k}, \mathrm{l})$, where steam cycle feedwater and oxygen are preheated. $\mathrm{CO}_{2}$-rich gas is then

\footnotetext{
${ }^{1}$ With the economic model assumptions presented in Section 4.3 and considering an average electricity selling price of $100 € / \mathrm{MWh}$ (same order of the obtained LCOE), the differential operating costs of the system without the FGD (i.e. additional limestone make-up: $200 € / \mathrm{h}$, additional consumption for first $\mathrm{CaCO}_{3}$ calcination of coal $62 € / \mathrm{h}$, power for oxygen production: $36 € / \mathrm{h}$, additional consumption for coal and limestone handling: $35 € / \mathrm{h}$ and power for $\mathrm{CO}_{2}$ compression: $95 € / \mathrm{h}$ ) and with the FGD (i.e. FGD power consumption: 333 $€ / \mathrm{h}$ and limestone consumption: $59 € / \mathrm{h}$ ) result in slightly higher operating costs for the CaL plant without the FGD $(428 € / \mathrm{h})$ than with the FGD $(392 € / \mathrm{h})$. This figure changes favoring the plant without the FGD if the spent CaO-rich sorbent is used for cement production and if capital costs for the FGD are accounted for (i.e. greenfield plants or retrofit of plants with no FGD).
}

compressed and purified in a $\mathrm{CO}_{2}$ purification unit (CPU) and delivered to a pipeline for $\mathrm{CO}_{2}$ transport and storage.

The CaL process has been calculated assuming a gas superficial velocity in the CFB reactors of $5 \mathrm{~m} / \mathrm{s}$, a carbonator height of $20 \mathrm{~m}$, a solids inventory (mass of solids per $\mathrm{m}^{2}$ of reactor cross-section) in the carbonator of $1000 \mathrm{~kg} / \mathrm{m}^{2}$, a fresh sorbent make-up ratio $\left(\mathrm{F}_{0} / \mathrm{F}_{\mathrm{CO} 2}\right)$ of 0.1 and a sorbent circulation rate $\left(\mathrm{F}_{\mathrm{Ca}} / \mathrm{F}_{\mathrm{CO} 2}\right)$ of 7.0 , ensuring a $\mathrm{CO}_{2}$ capture efficiency in the carbonator of $90 \%$ according to the model described in (Romano, 2012). The moderate carbonator height $(20 \mathrm{~m})$, compared to fluidized bed combustors of similar thermal power (40-50 m (Leckner et al., 2011)), is selected to reduce the heat transfer surface area in the carbonator riser and shift carbonator cooling from the riser to the external heat exchanger (o). In this way, better controllability of the carbonator temperature (kept at $650{ }^{\circ} \mathrm{C}$ at all loads to increase energy efficiency and keep high sorbent activity (Criado et al., 2018)) is obtained at part load, thanks to the easier controllability of heat removal from the fluidized bed external heat exchangers compared to the heat removed from the riser. However, it must be remarked that the carbonator height has small influence on the results presented in this paper.

In order to reduce the accumulation of ash in the CaL loop, PC is assumed to be fed in the calciner (Hilz et al., 2018), allowing to selectively separate the coarser sorbent particles from the fine ash in the cyclones, with different efficiencies (assumed equal to $99.9 \%$ and $90 \%$ for sorbent and ash respectively).

High temperature heat generated by the CaL process is recovered by the CaL power plant (CaLPP), which is also based on an USC steam cycle with reheat and live steam parameters of $560 / 580{ }^{\circ} \mathrm{C}$ and 270 / 56 bar. CaLPP steam cycle also recovers low temperature heat from the cooling of $\mathrm{CO}_{2}$-rich gas and from the intercoolers of the ASU and $\mathrm{CO}_{2}$ 
compression trains, by condensate preheating. The waste heat available at low temperature from ASU and CPU is such that the low-pressure feed water heaters before the deaerator are not needed (Fig. 2).

The "Reference" PCPP + CaL case has been calculated assuming that carbonator and calciner are sized to treat the nominal gas flow rate from the PCPP at full load. The system has been calculated with the proprietary code GS (GECOS, 2016) with the list of assumptions reported in Tables 4 and 5 for the CaL system and the CaLPP respectively. Properties of the main gaseous and solid streams of the plant are reported in Table 6 .

The energy balance of the PCPP + CaL plant and the key performance indicators are shown in Table 7 . About $45 \%$ of the total fuel input is consumed in the calciner of the CaL plant. The CaLPP steam turbine generates additional $636.1 \mathrm{MW}_{\mathrm{e}}$. The main additional auxiliary consumptions are associated to the CPU (122.1 $\left.\mathrm{MW}_{\mathrm{e}}\right)$, the ASU (70.6 $\mathrm{MW}_{\mathrm{e}}$ ), the power block auxiliaries $\left(26.2 \mathrm{MW}_{\mathrm{e}}\right)$, the carbonator fan (14.4 $\mathrm{MW}_{\mathrm{e}}$ ) and the calciner auxiliaries (13.1 $\left.\mathrm{MW}_{\mathrm{e}}\right)$. The resulting net power output is $387.6 \mathrm{MW}_{\mathrm{e}}$, corresponding to an increased power output by $51.9 \%$ with respect to the reference PCPP. Overall net electric efficiency of the PCPP + CaL plant is $37.5 \%$, with an efficiency penalty of $7.05 \%$ points with respect to the PCPP without $\mathrm{CO}_{2}$ capture, calculated with consistent assumptions. $\mathrm{CO}_{2}$ emissions of the plant are $79.1 \mathrm{~kg} / \mathrm{MWh}$, corresponding to a reduction of $89.9 \%$. The specific primary energy consumption for $\mathrm{CO}_{2}$ avoided (SPECCA) is $2.16 \mathrm{MJ} / \mathrm{kg}$.

As shown in Fig. 2, heat is transferred from the CaL system to the steam cycle through multiple heat exchange sections at different temperature ranges, as resumed in Table 8. The largest thermal power sources are the hot solids cooled from the calciner to the carbonator temperature $\left(\dot{Q}_{4}\right)$, which are assumed to be cooled in dedicated fluidized bed heat exchangers from $920^{\circ} \mathrm{C}$ to $850^{\circ} \mathrm{C}(\mathrm{m})\left(\dot{Q}_{4 . a}\right)$ and from $850^{\circ} \mathrm{C}$ to $650^{\circ} \mathrm{C}(\mathrm{n})\left(\dot{Q}_{4 . b}\right)$ before entering the carbonator. The second largest heat source is the calciner off gas (8), which is cooled in the convective pass (i) $\left(\dot{Q}_{3}\right)$. These two heat sources account for almost $50 \%$ of the total heat available. The third largest heat source (almost $17 \%$ of the heat available) is the heat available from the carbonator hot loop $\left(\dot{Q}_{1}\right)$ obtained from the carbonator riser waterwalls (c) $\left(\dot{Q}_{1 . a}\right)$ and from the fluidized bed external heat exchangers (EHE) (o) $\left(\dot{Q}_{1 . b}\right)$. The share of heat transferred in the riser and in the external heat exchangers is not distinguished in this work, as this will depend on the specific design of the carbonator heat transfer surface. The carbonator off gas (2), cooled in the carbonator convective pass (e) $\left(\dot{Q}_{2}\right)$ adds around $15 \%$ of the total available power. An additional small amount of heat $\left(\dot{Q}_{5}\right)$ is available from the $\mathrm{CaCO}_{3}$-rich solid purge (9), cooled in heat exchanger (p). The remaining thermal power (about 19\% of the total) is available from medium and low temperature sources $\left(<350^{\circ} \mathrm{C}\right)$, i.e. $\dot{Q}_{6}$ from $\mathrm{CO}_{2}$ coolers (j, l) and $\dot{Q}_{7}$ from ASU (q) and CPU (r) compressors intercoolers.

In Fig. 3, the cumulative temperature-heat diagram of the CaL heat sources and a graphical representation of the distribution of the steam cycle heat transfer sections are shown. It must be remarked that the actual LT heat recovered by condensate preheating (128 MW) is less than the total LT heat available from $\mathrm{CO}_{2}$ cooling and ASU and CPU intercoolers $\left(\dot{Q}_{6 . b}+\dot{Q}_{7}=222 \mathrm{MW}\right)$ and the remaining thermal power is released to the ambient by cooling water.

\section{CaL system with solids storage}

In the CaL system with solids storage, two silos are added in the plant flowsheet (drawn with dashed lines in Fig. 2). The high temperature silo stores calcined solids from the calciner outlet after partial cooling to $850^{\circ} \mathrm{C}$. This temperature has been selected to prevent accelerated sorbent deactivation for sintering, caused by long permanence time at high temperature. The low temperature storage silo collects carbonated solids from the carbonator outlet at $650{ }^{\circ} \mathrm{C}$. Thanks to this storage, the $\operatorname{load}^{2}$ of the calcination line and of the carbonator line can

\footnotetext{
${ }^{2}$ In this work, the term load $(L)$ is defined for the calciner as the percentage of
}

Table 4

Main assumptions for the design and calculation of the CaL system.

\begin{tabular}{|c|c|}
\hline \multicolumn{2}{|l|}{ Carbonator } \\
\hline Operating temperature, ${ }^{\circ} \mathrm{C}$ & 650 \\
\hline $\mathrm{CO}_{2}$ capture efficiency, $\%$ & 90 \\
\hline $\mathrm{SO}_{2}$ capture efficiency, $\%$ & 100 \\
\hline Inventory, $\mathrm{kg} / \mathrm{m}^{2}$ & 1000 \\
\hline Specific limestone make-up $\mathrm{F}_{0} / \mathrm{F}_{\mathrm{CO} 2}$ - & 0.10 \\
\hline Specific sorbent circulation $\mathrm{F}_{\mathrm{Ca}} / \mathrm{F}_{\mathrm{CO} 2}$, & 7.0 \\
\hline Mean gas superficial velocity, $\mathrm{m} / \mathrm{s}$ & 5 \\
\hline Riser height, $\mathrm{m}$ & 20 \\
\hline Cross section, $\mathrm{m}^{2}$ & 430 \\
\hline Cyclones efficiency on Ca solids, \% & 99.9 \\
\hline Cyclones efficiency on ash, \% & 90 \\
\hline Pressure loss in nozzles, bed and cyclone, $\mathrm{kPa}$ & 12 \\
\hline Pressure loss in convective pass, $\mathrm{kPa}$ & 3.5 \\
\hline Pressure loss in gas-gas heater, $\mathrm{kPa}$ & 1 \\
\hline Gas temperature at convective pass outlet, ${ }^{\circ} \mathrm{C}$ & 350 \\
\hline \multicolumn{2}{|l|}{ Calciner } \\
\hline Operating temperature, ${ }^{\circ} \mathrm{C}$ & 920 \\
\hline Mean gas superficial velocity, $\mathrm{m} / \mathrm{s}$ & 5 \\
\hline Riser height, $\mathrm{m}$ & 20 \\
\hline Cross section, $\mathrm{m}^{2}$ & 215 \\
\hline Oxygen concentration in oxidant stream, $\%_{\mathrm{vol}}$ & 50 \\
\hline Pressure losses in nozzles, bed and cyclone, $\mathrm{kPa}$ & 20 \\
\hline Oxygen concentration in $\mathrm{CO}_{2}$-rich gas, $\%_{\text {vol }}$ & 5 \\
\hline Recycle gas temperature, ${ }^{\circ} \mathrm{C}$ & 350 \\
\hline Pressure losses in convective pass, $\mathrm{kPa}$ & 3.5 \\
\hline \multicolumn{2}{|l|}{$A S U$} \\
\hline Oxygen purity, $\%_{\mathrm{vol}}$ & 95 \\
\hline Electric consumption, $\mathrm{kWh}_{\mathrm{e}} / \mathrm{t}_{\mathrm{O} 2}$ & 160.0 \\
\hline Heat for TSA bed regeneration, $\mathrm{kJ}_{\mathrm{th}} / \mathrm{kg}_{\mathrm{O} 2}$ & 18.3 \\
\hline Steam pressure for TSA bed regeneration, bar & 8 \\
\hline \multicolumn{2}{|l|}{$\mathrm{CO}_{2}$ compression and purification unit } \\
\hline Electric consumption, $\mathrm{kWh}_{\mathrm{e}} / \mathrm{t}_{\mathrm{CO} 2}$ & 115.8 \\
\hline Final $\mathrm{CO}_{2}$ purity, $\%$ & $>96$ \\
\hline Final $\mathrm{CO}_{2}$ pressure, bar & 110 \\
\hline \multicolumn{2}{|l|}{ Auxiliaries } \\
\hline Fans isentropic efficiency, $\%$ & 80 \\
\hline Fans electric-mechanical efficiency, \% & 94 \\
\hline Coal milling and handling systems, $\mathrm{kJ}_{\mathrm{e}} / \mathrm{kg}_{\text {coal }}$ & 50 \\
\hline Limestone handling systems, $\mathrm{kJ}_{\mathrm{e}} / \mathrm{kg}_{\text {limestone }}$ & 90 \\
\hline Purge handling systems, $\mathrm{kJ}_{\mathrm{e}} / \mathrm{kg}_{\text {purge }}$ & 100 \\
\hline Balance of plant (BOP), $\%$ of fuel energy input & 0.15 \\
\hline
\end{tabular}

be decoupled, i.e. the calciner can produce a lower flow rate of regenerated sorbent than the instantaneous requirement of the carbonator by emptying the hot storage and vice-versa.

In Fig. 4, a representative trend of significant variables during a given operation period is shown for a CaL system with the calcination line with a size of around $75 \%$ of the reference CaL system without storage and an overall storage volume (sum of low temperature and high temperature silos) equal to $150 \%$ of the carbonator internal volume. In Fig. 5, the general operating logic of the system is graphically described.

1 The load of the PCPP is lower than the nominal load of the calciner

\section{(footnote continued)}

actual fuel input compared to the maximum fuel input in the reference case with both reactors designed at PCPP nominal point, as discussed in Section 2. For the calculation of the carbonator load $(L)$, the gas flow rate treated in the carbonator is adopted as sizing parameter. The relative load $\left(L^{r e l}\right)$ is defined as the percent load with respect to the nominal load $L^{\text {nom }}$ allowed by the actual size of the component. For example, if the calciner line is sized for a maximum combustion power equal $80 \%$ of the reference case without storage (1357 $\mathrm{MW}_{\mathrm{LHV}}$ ) and has an instantaneous combustion power at time $t$ of $800 \mathrm{MW}_{\mathrm{LHV}}$, the calciner has a nominal load $L^{\text {nom }}=80 \%$, an actual load $L^{t}=800 / 1357=59 \%$ and a relative load $L^{\text {rel }}=800 /(1357 \cdot 0.8)=73.7 \%$. 
Table 5

Main assumptions for the design and calculation of the CaPP plant.

\begin{tabular}{ll}
\hline Steam cycle & \\
Boiler feed water temperature, ${ }^{\circ} \mathrm{C}$ & 307 \\
Boiler feed water pressure, bar & 320 \\
SH/RH live steam temperature, ${ }^{\circ} \mathrm{C}$ & $560 / 580$ \\
SH/RH live steam pressure, bar & $270 / 56$ \\
SH/RH pressure loss at turbine admission valve, \% & 2 \\
RH pressure loss, \% & 6.7 \\
Condensing pressure, bar & 0.048 \\
Number of FWHs (including deaerator) - & 6 \\
Pinch-point $\Delta \mathrm{T}$ in FWHs, ${ }^{\circ} \mathrm{C}$ & 3 \\
Steam pressure loss in deaerator/surface FWHs, \% & $7 / 3$ \\
Feed water pump hydraulic efficiency, \% & 85 \\
Feed water pump mechanical/electric efficiency, \% & $98 / 95$ \\
\hline Steam turbine & \\
Rotational speed, rpm & 3000 \\
Number of HP/IP/LP parallel flows - & $1 / 2 / 4$ \\
Isentropic efficiency, \% & Calculated \\
Last stage turbine blade height, mm & 1016 \\
Last stage peripheral velocity at mean diameter, m/s & 433 \\
Last stage exhaust area (per flow), m ${ }^{2}$ & 8.82 \\
Exhaust steam velocity, m/s & 220 \\
Generator mechanical efficiency, \% & 99.6 \\
Generator electrical efficiency, $\%$ & 98.5 \\
\hline
\end{tabular}

$\left(L_{P C P P}^{t}<L_{\text {calc }}^{\text {nom }}\right.$ ), therefore the flow rate of hot regenerated sorbent produced in the calciner is more than the flow rate of CaO-rich sorbent needed in the carbonator $\left(\dot{m}_{\text {calc }}^{\text {out }}>\dot{m}_{\text {carb }}^{\text {need }}\right)$ (Fig. $\left.4 \mathrm{a}\right)$. The following two conditions may occur under such circumstances:

- The high temperature storage is full $\left(H T_{S O C}=1\right)$ and the storage capacity of calcined sorbent is completely exploited (Fig. 4.b): the load of the calcination line reduces to match the PCPP and carbonator load $\left(L_{\text {calc }}^{t}=L_{P C P P}^{t}\right)$ and produce the exact amount of calcined sorbent needed for $\mathrm{CO}_{2}$ capture in the carbonator.

- The high temperature silo has storage capacity available $\left(H T_{S O C}<1\right)$ : the calcination line operates at its design load $\left(L_{\text {calc }}^{t}=L_{\text {calc }}^{\text {nom }}\right)$ (Fig. 4.a) and calcined sorbent is accumulated in the HT silo, while carbonated sorbent is removed from the LT silo (Fig. 4b).

2 The load of the PCPP is higher than the nominal load of the calciner $\left(L_{P C P P}^{t}>L_{\text {calc }}^{\text {nom }}\right)$ (Fig. $4 \mathrm{a}$ ), therefore the flow rate of hot regenerated sorbent produced in the calciner is less than the flow rate required in the carbonator for $\mathrm{CO}_{2}$ capture $\left(\dot{m}_{\text {calc }}^{\text {out }}<\dot{m}_{\text {carb }}^{\text {need }}\right)$. The following two conditions may occur under such circumstances:

- The low temperature silo has stored solids available $\left(L T_{S O C}>1\right)$ : the carbonator and the calciner operate at their design load (relative load $=100 \%: \quad L_{\text {calc }}^{t}=L_{\text {calc }}^{\text {nom }}, \quad L_{\text {carb }}^{t}=L_{\text {carb }}^{\text {nom }}=L_{P C P P}^{t}$ )
(Fig. 4a), calcined sorbent is extracted from the HT silo while carbonated sorbent is accumulated in the LT silo (Fig. 4b).

$O$ The high temperature storage is empty $\left(H T_{S O C}=0\right)$ and the low temperature storage is full (Fig. 4b): the sorbent flow rate to the carbonator reduces, matching the sorbent flow rate produced in the calciner $\left(\dot{m}_{\text {calc }}^{\text {out }}<\dot{m}_{\text {carb }}^{\text {need }}\right)$. In this condition, $\mathrm{CO}_{2}$ emissions increase and $\mathrm{CO}_{2}$ capture efficiency reduces $\left(C C E^{t}<C C E^{\text {nom }}\right)$ (Fig. 4c), because of a reduction of the $F_{C a} / F_{0}$ ratio in the carbonator $\left(\left(F_{C a} / F_{0}\right)^{t}<\left(F_{C a} / F_{0}\right)^{n o m}\right)$.

How often the possible operating conditions occur, largely depends on the size of the calciner line, on the size of the silos for solids storage and on the power plant production plan.

\section{Annual simulations methodology}

A model of the integrated PCPP + CaL plant with solids storage is developed in Excel and Visual Basic to perform annual simulations. Simulations are carried out with 1-hour time step over one week and results are prorated for the whole year considering a fixed annual availability equal to $90 \%$, equivalent to 47 weeks. Coal and $\mathrm{CaCO}_{3}$ consumption, total electric energy output and $\mathrm{CO}_{2}$ emission are calculated on a yearly basis. Economic analysis allows calculating the cost of the system, the LCOE and the cost of $\mathrm{CO}_{2}$ avoided (CCA). For a given production plan of the PCPP provided in input, techno-economic optimization can be carried out by grid search method varying the size of the calciner and the storage system.

\subsection{Operation profiles}

The analysis is carried out on two different PCPP power production plans (Table 9). Medium Capacity Factor ("Medium CF") scenario is characterized by a daily load pattern typical of coal power plants in central Europe, showing two full load periods from 6 a.m. to $1 \mathrm{pm}$ and from $7 \mathrm{pm}$ to $9 \mathrm{pm}$ in working days from Monday to Friday and a $50 \%$ load in the other hours of the day. During the weekend, the PCPP works at 50\% load. The Low Capacity Factor ("Low CF") scenario has the same profile of the Medium CF case, but with a lower minimum PCPP load equal to $30 \%$.

Table 9 reports the load pattern information for the two investigated cases with the average PCPP flue gases mass flow rate on daily, weekend and weekly basis.

\subsection{Thermodynamic model}

A simplified model has been developed to calculate the power

Table 6

Mass flow rate and composition of the main gas and solid streams of the CaL plant.

\begin{tabular}{|c|c|c|c|c|c|c|}
\hline Gas streams & $\begin{array}{l}\text { Flue gas from } \\
\text { PCPP (1) }\end{array}$ & $\begin{array}{l}\text { Lean-CO } \\
\text { Carbona }\end{array}$ & & $\begin{array}{l}\mathrm{CO}_{2} \text {-rich gas from Calciner } \\
\text { (8) }\end{array}$ & $\begin{array}{l}\text { Recycled } \mathrm{CO}_{2} \text {-rich gas to } \\
\text { calciner (7) }\end{array}$ & $\begin{array}{l}\mathrm{O}_{2} \text {-rich gas from } \\
\text { ASU (6) }\end{array}$ \\
\hline mass flow rate, $\mathrm{kg} / \mathrm{s}$ & 743.8 & 597.2 & & 493.5 & 160.6 & 129.7 \\
\hline Molar flow rate, $\mathrm{kmol} / \mathrm{s}$ & 24.87 & 21.55 & & 12.39 & 4.03 & 4.03 \\
\hline $\mathrm{CO}_{2}, \%$ vol. & 14.86 & 1.71 & & 79.46 & 79.46 & 0.00 \\
\hline Ar, \%vol. & 0.88 & 1.02 & & 1.45 & 1.45 & 3.00 \\
\hline $\mathrm{N}_{2}, \%$ vol. & 74.13 & 85.60 & & 1.32 & 1.32 & 2.00 \\
\hline $\mathrm{O}_{2}, \%$ vol. & 2.91 & 3.36 & & 5.00 & 5.00 & 95.00 \\
\hline $\mathrm{H}_{2} \mathrm{O}$, \%vol. & 7.20 & 8.32 & & 12.77 & 12.77 & 0.00 \\
\hline $\mathrm{SO}_{2}, \%$ vol. & 0.004 & 0.00 & & 0.00 & 0.00 & 0.00 \\
\hline Solids streams & \multicolumn{2}{|c|}{ CaO-rich solids to the calciner (4) } & \multicolumn{2}{|c|}{ CaO-rich solids to the carbonator (3) } & Solids purge (9) & Sorbent make up (10) \\
\hline mass flow rate, $\mathrm{kg} / \mathrm{s}$ & 1682.9 & & \multicolumn{2}{|l|}{1563.8} & 14.5 & 37.0 \\
\hline $\mathrm{CaO}, \%$ wt. & 74.21 & & \multicolumn{2}{|l|}{92.85} & 74.21 & 0.00 \\
\hline $\mathrm{CaCO}_{3}, \%$ wt. & 19.55 & & \multicolumn{2}{|l|}{0.00} & 19.55 & 100.00 \\
\hline $\mathrm{CaSO}_{4}, \%$ wt. & 5.57 & & \multicolumn{2}{|l|}{6.06} & 5.57 & 0.00 \\
\hline Ash, \%wt. & 0.67 & & \multicolumn{2}{|l|}{1.09} & 0.67 & 0.00 \\
\hline
\end{tabular}


Table 7

Energy balance of the PCPP and the CaLPP plants and the key performance indicators.

\begin{tabular}{|c|c|}
\hline \multicolumn{2}{|l|}{ PCPP } \\
\hline Coal input, $\mathrm{kg} / \mathrm{s}$ & 66.607 \\
\hline Coal thermal input, $\mathrm{MW}_{\mathrm{LHV}}$ & 1676.5 \\
\hline Steam turbine & 804.84 \\
\hline Boiler feed water pump & -26.24 \\
\hline Condensate extraction pump & -0.64 \\
\hline Condenser auxiliaries & -6.25 \\
\hline Coal milling and handling & -3.33 \\
\hline Filters and ash handling & -1.88 \\
\hline Flue gas desulfurizer & -3.33 \\
\hline Primary air fan & -1.26 \\
\hline Secondary air forced draft fan & -2.20 \\
\hline Induced draft fan & -9.98 \\
\hline BOP & -2.51 \\
\hline Net electric power output, MW & 747.22 \\
\hline Gross electric efficiency, $\%_{\mathrm{LHV}}$ & 48.01 \\
\hline Net electric efficiency, $\%_{\mathrm{LHV}}$ & 44.57 \\
\hline Direct $\mathrm{CO}_{2}$ emission at stack, $\mathrm{kg} / \mathrm{s}$ & 162.45 \\
\hline $\mathrm{CO}_{2}$ specific emission, $\mathrm{kg} / \mathrm{MWh}$ & 782.70 \\
\hline \multicolumn{2}{|l|}{ Reference CaLPP } \\
\hline Calciner coal input, $\mathrm{kg} / \mathrm{s}$ & 53.92 \\
\hline Calciner coal thermal input, $\mathrm{MW}_{\mathrm{LHV}}$ & 1357.2 \\
\hline CaLPP steam turbine & 636.07 \\
\hline CaLPP boiler feed water pump & -20.74 \\
\hline CaLPP condensate extraction pump & -0.50 \\
\hline CaLPP condenser auxiliaries & -4.94 \\
\hline CaLPP coal milling and handling & -2.53 \\
\hline CaLPP purge and limestone handling & -4.78 \\
\hline CaLPP forced draft fans & -2.84 \\
\hline CaLPP $\mathrm{CO}_{2}$ recirculation fan & -5.36 \\
\hline CaLPP carbonator fan & -11.97 \\
\hline CaLPP BOP & -2.04 \\
\hline ASU & -70.61 \\
\hline $\mathrm{CO}_{2}$ compression & -122.1 \\
\hline Net electric power output of CaLPP, MW & 387.64 \\
\hline CaLPP net electric efficiency, $\%_{\mathrm{LHV}}$ & 28.56 \\
\hline \multicolumn{2}{|l|}{ Reference PCPP + CaL } \\
\hline PCPP net power output & 750.54 \\
\hline Net electric power output, MW & 1138.2 \\
\hline Total coal input, $\mathrm{kg} / \mathrm{s}$ & 120.53 \\
\hline Total coal thermal input, $\mathrm{MW}_{\mathrm{LHV}}$ & 3033.7 \\
\hline Gross electric efficiency, $\%_{\mathrm{LHV}}$ & 47.50 \\
\hline Net electric efficiency, $\%_{\mathrm{LHV}}$ & 37.52 \\
\hline Net electric efficiency penalty, \%pts. & -7.05 \\
\hline Direct $\mathrm{CO}_{2}$ emission at the stack, $\mathrm{kg} / \mathrm{s}$ & 16.24 \\
\hline $\mathrm{CO}_{2}$ vented from $\mathrm{CPU}, \mathrm{kg} / \mathrm{s}$ & 8.77 \\
\hline Total $\mathrm{CO}_{2}$ emission, $\mathrm{kg} / \mathrm{s}$ & 25.01 \\
\hline $\mathrm{CO}_{2}$ specific emission, $\mathrm{kg} / \mathrm{MWh}$ & 79.10 \\
\hline $\mathrm{CO}_{2}$ avoided, $\%$ & 89.9 \\
\hline SPECCA, MJ/kg $\mathrm{CO} 2_{2}$ & 2.16 \\
\hline
\end{tabular}

* PCPP net power output does not include the consumption of the FGD when integrated with the CaL capture system.

generated by the CaLPP at different loads of the carbonator and the calciner lines. The model considers the impact on the steam cycle efficiency of:

- the ratio between high temperature (HT) heat (used for water economization, evaporation, superheating and reheating) and low temperature (LT) heat (used for water preheating in parallel or in substitution of the FWHs) available from the different heat sources (Fig. 3), which is dependent on the relative carbonator and calciner loads;

- the effect of the reduced steam flow rate through the steam cycle, causing a reduction of the cycle efficiency at part load, mainly because of the reduction of the regenerative bleeding pressure and of the steam turbine efficiency.

In order to estimate the effect of different HT/LT heat ratios, the
Table 8

Heat exchange sections in the CaL plant designed and operated at full load.

\begin{tabular}{lllll} 
& & \multicolumn{2}{l}{ Heat available } & \multirow{2}{*}{$\mathrm{T}_{\max } \mathrm{T}_{\min }{ }^{\circ} \mathrm{C}$} \\
\cline { 3 - 4 } & & $\mathrm{MW}$ & $\%$ & \\
\hline Carbonator riser and EHE & $\dot{Q}_{1}^{\text {ref }}$ & 247.1 & 16.75 & $650-650$ \\
Carbonator convective pass & $\dot{Q}_{2}^{\text {ref }}$ & 211.9 & 14.37 & $650-350$ \\
Purge cooler & $\dot{Q}_{5}^{\text {ref }}$ & 5.8 & 0.39 & $650-231.5$ \\
Calciner convective pass & $\dot{Q}_{3}^{\text {ref }}$ & 349.4 & 23.69 & $920-350$ \\
Calcined solids coolers HT & $\dot{Q}_{4 . a}^{r e f}$ & 99.6 & 6.75 & $920-850$ \\
Calcined solids coolers LT & $\dot{Q}_{4 . b}^{r e f}$ & 284.4 & 19.28 & $850-650$ \\
MT CO & & & \\
LT Cooler & $\dot{Q}_{6 . a}$ ref & 54.4 & 3.69 & $350-180$ \\
LT ASU and CPU intercoolers & $\dot{Q}_{6 . b}^{r e f}$ & 27.0 & 1.83 & $155-70$ \\
Total & $\dot{Q}_{7}^{\text {ref }}$ & 195.3 & 13.24 & $140-70$ \\
\hline & & 1474.9 & 100 & \\
\hline
\end{tabular}

efficiency of the CaLPP has been calculated with the GS code for different calciner/carbonator load ratio $\left(L R=L_{\text {calc }}^{t} / L_{\text {carb }}^{t}\right)$ in the 0.5-3.3 range. Available thermal power $\dot{Q}_{1}, \dot{Q}_{2}, \dot{Q}_{4 . b}$ and $\dot{Q}_{5}$ are proportional to the carbonator and the PCPP load, while $\dot{Q}_{3}, \dot{Q}_{4 . a}, \dot{Q}_{6}$ and $\dot{Q}_{7}$ are proportional to the calciner load. A lower load of the calciner line with respect to the carbonator one, involves a lower availability of heat at medium-low temperature $\left(\dot{Q}_{6 . b}\right.$ and $\left.\dot{Q}_{7}\right)$ compared to the high temperature heat input $\left(\dot{Q}_{H T}=\dot{Q}_{1}+\dot{Q}_{2}+\dot{Q}_{4 . a}+\dot{Q}_{4 . b}+\dot{Q}_{5}\right)$. As a result, the share of heat from $\mathrm{CO}_{2}$ cooling for high pressure water preheating reduces (Fig. 6) and the relative flow rate of high-pressure regenerative bleedings increases.

To calculate the electric power output, a high temperature heat conversion efficiency $\eta_{Q_{H T}}$ has been defined in Eq. (1), as the ratio between the net electric power output of the steam cycle $\dot{W}_{\text {cycle }}$ (calculated as the turbine power output minus the absorption of pumps and the condenser auxiliaries) and the high temperature heat input $\dot{Q}_{H T}$, calculated as the sum of the high temperature heat from the carbonator and the calciner lines. The high temperature heat from the carbonator line is calculated as the product between the actual carbonator load $\left(L_{\text {carb }}^{t}\right)$ and the sum of the reference thermal power $\dot{Q}_{i}^{\text {ref }}$ (where $i \in\{1,2,4 b, 5\})$ reported in Table 8. Similarly, the high temperature heat from the calciner line is calculated as the product between the actual calciner load $\left(L_{\text {calc }}^{t}\right)$ and the sum of the reference thermal power $\dot{Q}_{i}^{\text {ref }}$ (where $i \in\{3,4 a\}$ ).

Different cases with different calciner/carbonator load ratio $L R$ have been calculated with GS code, obtaining the $\eta_{Q_{H T}}=f(L R)$ relation shown in Fig. 6 and regressed $\left(R^{2}=0.9993\right)$ with the second degree polynomial of Eq. (2).

$\eta_{Q_{H T}}=\frac{\dot{W}_{c y c l e}}{\dot{Q}_{H T}}=\frac{\dot{W}_{c y c l e}}{\left(\dot{Q}_{1}^{\text {ref }}+\dot{Q}_{2}^{\text {ref }}+\dot{Q}_{4 . b}^{\text {ref }}+\dot{Q}_{5}^{\text {ref }}\right) L_{\text {carb }}^{t}+\left(\dot{Q}_{3}^{\text {ref }}+\dot{Q}_{4 . a}^{\text {ref }}\right) L_{c a l c}^{t}}$

$\eta_{Q_{H T}}=4.976210^{-1}+1.288110^{-2} \cdot L R-1.50010^{-3} \cdot L R^{2}$

With this approach, for any given load of carbonator $\left(L_{c a r b}^{t}\right)$ and calciner $\left(L_{\text {calc }}^{t}\right)$, high temperature heat available $\dot{Q}_{H T}$ (denominator of Eq. (1)) and high temperature heat conversion efficiency $\eta_{Q H T}$ (Eq. (2)) are calculated. The steam cycle power output $\dot{W}_{\text {cycle }}$ is therefore computed as the product between $\dot{Q}_{H T}$ and $\eta_{Q_{H T}}$. This procedure can be used to calculate the steam cycle power output at nominal operating conditions (i.e. when $L_{\text {carb }}^{t}=L_{\text {carb }}^{\text {nom }}$ and $L_{\text {calc }}^{t}=L_{\text {calc }}^{\text {nom }}$ ) and to obtain a first estimation of the CaLPP off-design power output $\dot{W}_{\text {cycle }}^{\text {off }}$, when load refer to off-design operating conditions. For the off-design power output, it represents an approximated estimation of the power output, as it does not include any penalty related to the off-design operation of the steam cycle components. Therefore, for part-load efficiency calculation, a penalty is accounted for by means of a correction factor $\eta_{\text {off }}^{\text {corr }}$ expressed 

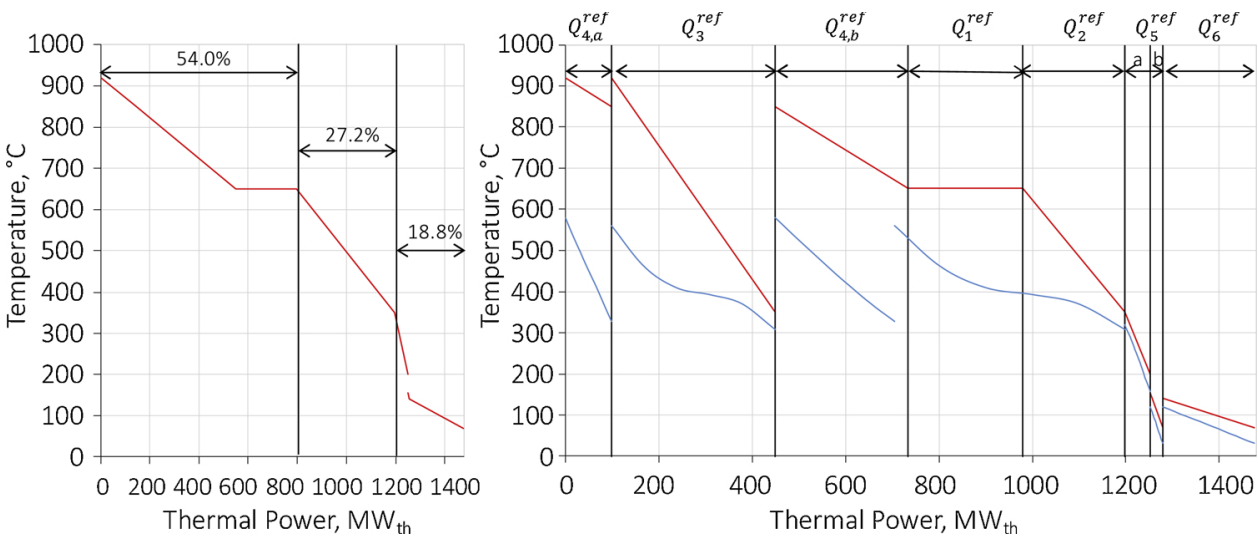

Fig. 3. Cumulative temperature-heat chart of the heat available from the CaL system (left) and possible location of the heat transfer sections (right).

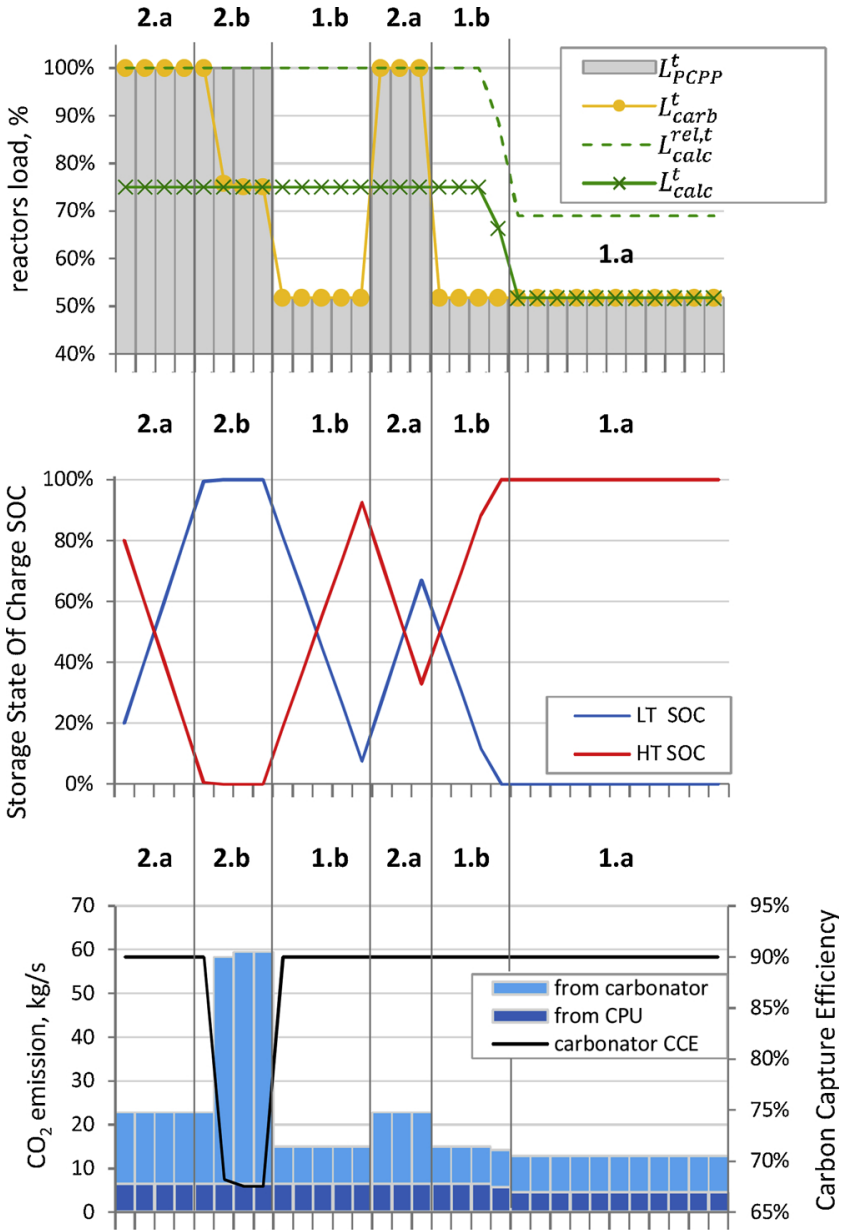

Hour of the day

Fig. 4. Representative quantities during the possible operating modes of the CaL system with solids storage: a) PCPP, carbonator and calciner load b) State Of Charge of hot and cold storage vessels, c) $\mathrm{CO}_{2}$ emissions and $\mathrm{CO}_{2}$ capture efficiency.

as function of the ratio between the off-design and the nominal cycle power output $\left(\dot{W}_{\text {cycle }}^{\text {off }} / \dot{W}_{\text {cycle }}^{\text {nom }}\right)$. Information on USC part load performance from four different references (Fan et al., 2017; Hogg, 2005; IEA, 2010; Spliethoff, 2010) are fitted with the $5^{\text {th }}$ degree polynomial Eq. (3) as shown in Fig. 7. $\eta_{\text {off }}^{\text {corr }}=\sum_{i=0}^{5} A_{i}\left(\frac{\dot{W}_{\text {cycle }}^{\text {off }}}{\dot{W}_{\text {cycle }}^{\text {nom }}}\right)^{i}$

$A_{0}=0.7131, A_{1}=1.1105, A_{2}=-1.8943, A_{3}=1.7797$,

$A_{4}=-0.9163, A_{5}=0.2074$

Net power output of the CaLPP in off-design operation $\dot{W}_{\text {CaLPP }}^{\text {off }}$ is then calculated with Eq. (4), by subtracting from the power output $\left(\dot{W}_{\text {cycle }}^{\text {off }} \bullet \eta_{\text {off }}^{\text {corr }}\right.$ ), the power consumed by the auxiliaries on the carbonator side (carbonator and stack fans) and on the calciner side (ASU, CPU, fans, coal and sorbent handling). Electric consumption of auxiliaries is obtained as the product between the electric consumptions calculated for the reference case $\dot{W}_{a u x}^{r e f}$ and the corresponding carbonator or calciner loads in the actual operation $L^{t}$.

$$
\begin{aligned}
\dot{W}_{\text {CaLPP }}^{\text {off }}= & \dot{W}_{\text {cycle }}^{\text {off }} \bullet \eta_{\text {off }}^{\text {corr }}-\dot{W}_{\text {aux }}^{\text {off }}=\dot{W}_{\text {cycle }}^{\text {off }} \cdot \eta_{\text {off }}^{\text {corr }}-\dot{W}_{\text {aux }, \text { carb }}^{\text {ref }} \cdot L_{\text {carb }}^{t} \\
& -\dot{W}_{\text {aux }, \text { calc }}^{\text {ref }} \cdot L_{\text {calc }}^{t}
\end{aligned}
$$

A similar approach is used to calculate the part load performance of the PCPP. Knowing the gross power output, the efficiency is evaluated with Eq. (3) allowing calculating the coal consumption and the flue gases mass flow rate fed to the carbonator reactor. Net power output from the PCPP is obtained by subtracting from the gross power output the consumption of boiler auxiliaries, assumed proportional to the fuel consumption.

In this work the entire flow rate of the PCPP flue gas is always fed to the carbonator. If the carbonator load is higher than the calciner one and there is no calcined sorbent available in the HT silo (i.e. condition 2.b discussed in Section 3), the carbonator operates at $F_{\mathrm{Ca}} / F_{\mathrm{CO} 2}$ ratio lower than the nominal one, leading to an overall $\mathrm{CO}_{2}$ capture efficiency lower than the design point. Such operating condition would lead to a sorbent conversion higher than the nominal one, because of the higher average $\mathrm{CO}_{2}$ partial pressure and the higher sorbent residence time in the carbonator. On the contrary, when the PCPP works at reduced load, the gas and solids residence time in the carbonator increases and higher CCE and sorbent conversion are expected. In both cases we assumed to keep a constant sorbent conversion equal to the design value by properly modifying the $F_{0} / F_{\mathrm{CO} 2}$ ratio. This assumption allows to significantly simplify the calculations, since (i) solid streams composition remains constant, leading to uniform composition of the solids stored in the LT silo and (ii) $\mathrm{CO}_{2}$ capture efficiency in the carbonator is proportional to $F_{\mathrm{Ca}} / F_{\mathrm{CO} 2}$ ratio (Fig. 8).

\subsection{Economic model}

An economic model has been defined to estimate the capital and operating costs of the system and the levelized cost of electricity. $L C O E$ is calculated with Eq. (5) as the sum of the annualized capital cost 


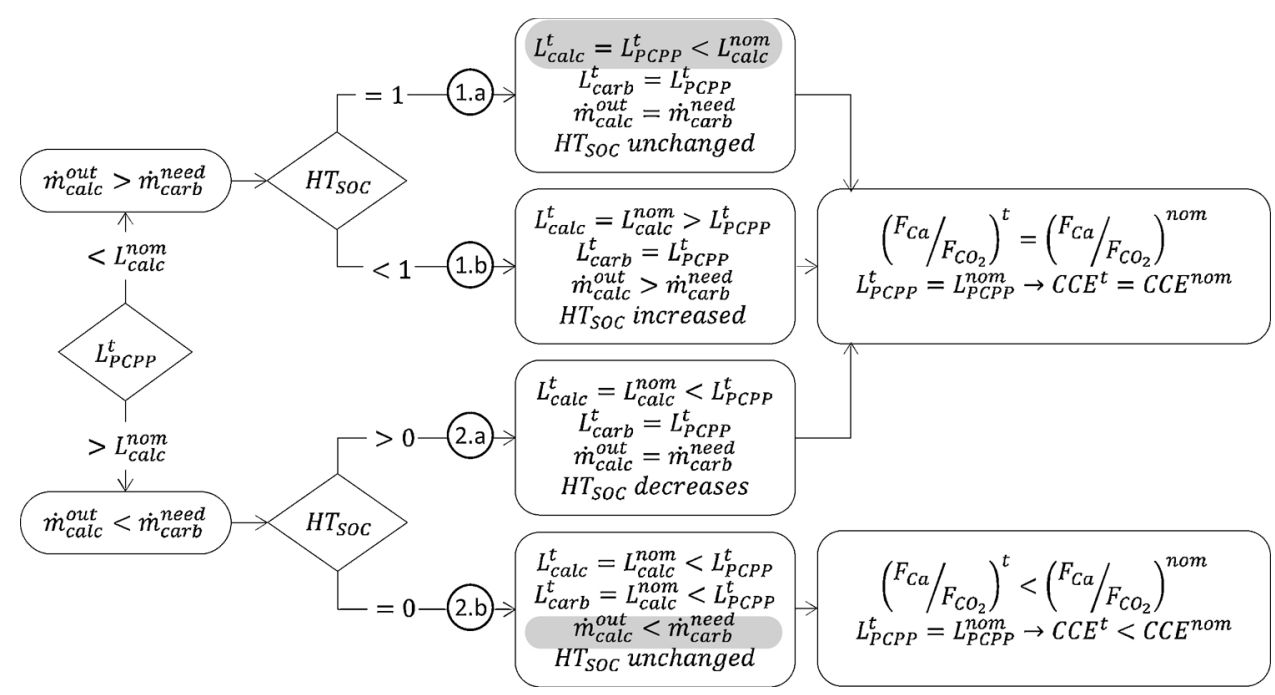

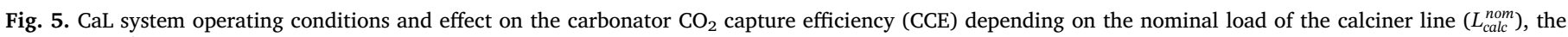

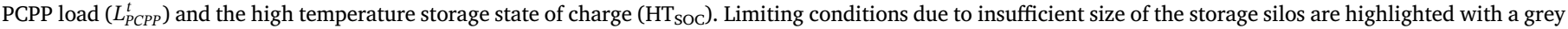

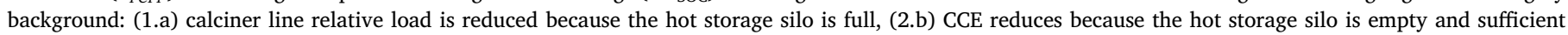
sorbent flow rate cannot be provided to the carbonator.

Table 9

Medium CF and Low CF scenarios for the PCPP operation and average flue gas flow rates for the CaL system design.

\begin{tabular}{llll}
\hline \multicolumn{2}{c}{ PCPP weekly power production plan } \\
\hline \multicolumn{2}{c}{ Mon-Fri } & Sat-Sun \\
\cline { 2 - 3 } & $\begin{array}{l}\text { 6 am-1 pm } \\
7 \text { pm-9 pm }\end{array}$ & $\begin{array}{l}10 \text { pm-5 am } \\
2 \text { pm-6 pm }\end{array}$ & $\begin{array}{l}\text { Full day } \\
(12 a m-23 p m)\end{array}$ \\
\hline Medium CF & $100 \%$ & $50 \%$ & $50 \%$ \\
Low CF & $100 \%$ & $30 \%$ & $30 \%$ \\
\hline
\end{tabular}

Averages relative value on flue gases mass flow rate

\begin{tabular}{llll}
\hline & Mon-Fri & Sat-Sun & week \\
\hline Medium CF & $73.86 \%$ & $51.73 \%$ & $67.54 \%$ \\
Low CF & $63.56 \%$ & $32.72 \%$ & $54.75 \%$ \\
\hline
\end{tabular}

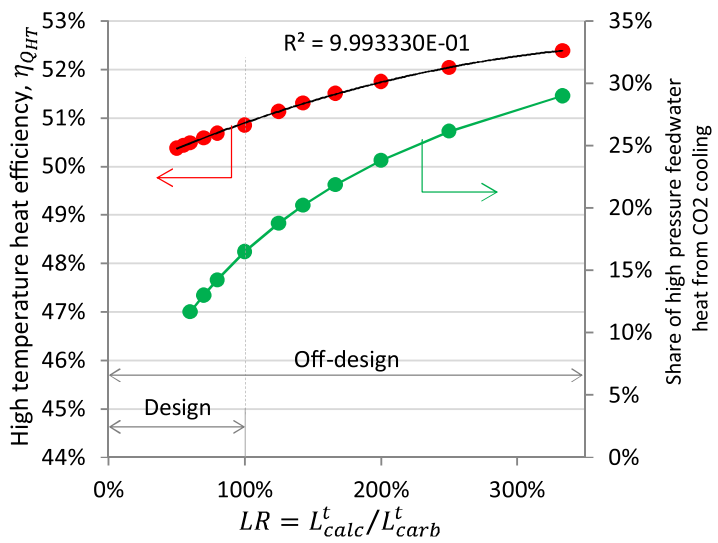

Fig. 6. Steam cycle efficiency referred to the high temperature heat input $\eta_{Q_{H T}}$ and share of heat from $\mathrm{CO}_{2}$ cooling for high pressure water preheating. Cases with LR $\leq 1$ are representative of possible CaL design while off-design conditions can span up to LR $=333 \%$ (i.e. PCPP working at $30 \%$ load and calciner at $100 \%$ load in cases with a sufficiently large storage).
$\left(C A P E X_{a}\right)$ and the yearly operation and maintenance cost OPEX divided by the net electric energy produced by the plant in a year $E E_{n e t}$. Annualized capital cost $C A P E X_{a}$ [ $€ /$ year] is calculated with Eq. (6) from the total as-spent cost of the plant (TASC), through the capital charge factor $(C C F)$, assumed equal to 0.11 year $^{-1}$. OPEX [€/year] are calculated with Eq. (7), as the sum of the cost of coal, the cost of limestone, the cost of $\mathrm{CO}_{2}$ emissions (associated to the carbon tax, when relevant), the cost for $\mathrm{CO}_{2}$ transport and storage, the other variable O\&M cost and the fixed O\&M cost.

$L C O E=\frac{C A P E X_{a}}{E E_{\text {net }}}+\frac{O P E X}{E E_{\text {net }}}$

$C A P E X_{a}=C C F \cdot T A S C$

$\mathrm{OPEX}=C_{\text {coal }}^{\text {year }}+C_{\mathrm{CaCO} 3}^{\text {year }}+C_{C T}^{\text {year }}+C_{T \& S}^{\text {year }}+C_{O \& M, \mathrm{var}}^{\text {year }}+C_{O \& M, f i x e d}^{\text {year }}$

Capital cost of each component and unit operation is computed with a scaling function (8), by correcting the reference cost $C^{\text {ref }}$ of an item with reference size $S^{r e f}$ with an exponential law with exponent $f$. Parameters for capital cost estimation through Eq. (8) are summarized in Table 10 and are derived from NETL/DOE reports (Chou et al., 2011; Fout et al., 2015; Turner et al., 2012; Turner and Pinkerton, 2013), Thermoflex software (Thermoflow Inc., 2018) and personal communications with industrial manufacturers.

$C=C^{r e f}\left(\frac{S}{S^{r e f}}\right)^{f}$

For the sake of simplicity, the economic analysis is set up considering a greenfield plant, i.e. assuming the same $C C F$ for the components of the PCPP and of the CaL system. For the same reason, the Capex of the FGD are excluded in the PCPP + CaL power plant.

After summing all the capital cost items and obtaining the total plant cost (TPC), the TASC of the plant is obtained by multiplying the TPC by 1.224 to include other costs (e.g. owner's costs, financing costs, pre-production costs, inventory capital) and by 1.134 as TASC multiplier, corresponding to a 35 years, low risk investment.

The main assumptions used for the calculation of the LCOE are reported in Table 11. Fixed and variable Opex are derived from (Chou et al., 2011) 


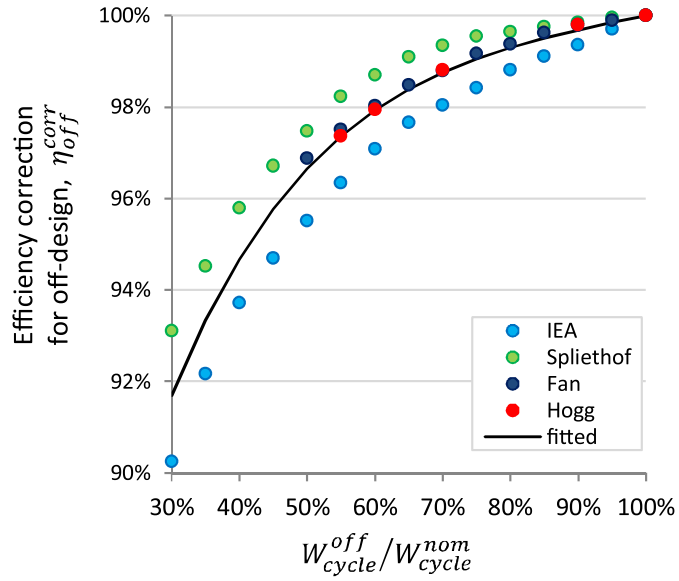

Fig. 7. Off-design efficiency correction factor $\eta_{\text {off }}^{\text {corr }}$ as function of the power plant relative load.

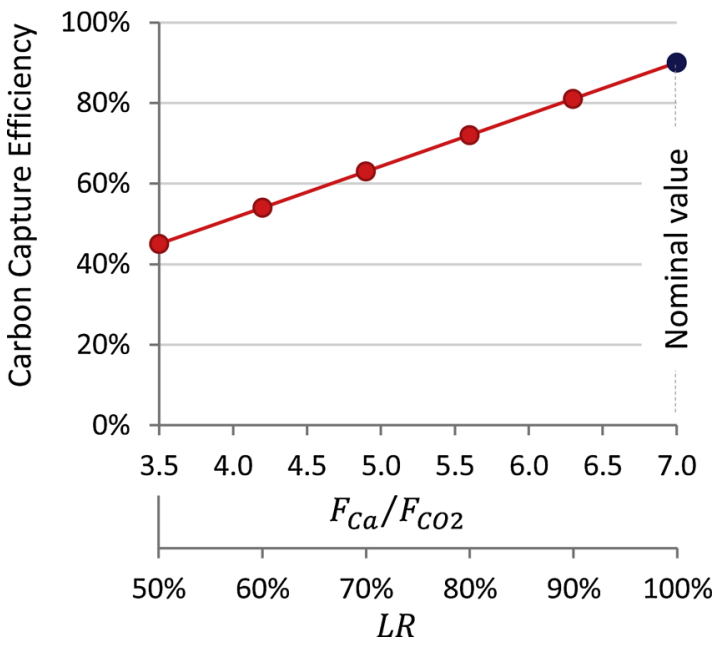

Fig. 8. $\mathrm{CO}_{2}$ capture efficiency for different calciner/carbonator Load Ratio (LR) under the assumption of constant sorbent conversion.

\section{Results}

\subsection{Preliminary results}

A preliminary analysis is carried out for both scenarios identifying the storage size that allows a complete cycling on daily and on weekly basis.

- Daily cycling (Fig. 9.a): calciner line is designed at the PCPP workday average load and the storage is large enough to complete a daily cycle without being saturated. At this condition the calciner line always works at its nominal load from Monday to Friday, while the carbonator follows the PCPP operation. During the weekend, the high temperature storage is rapidly saturated and calciner line load is reduced (operating condition 1.a in Fig. 4. a). With this configuration the total volume of the storage (sum of hot and cold storage) is around $18,850 \mathrm{~m}^{3}$ for the Medium CF scenario (namely $250 \%$ the volume of the carbonator) and $26,385 \mathrm{~m}^{3}$ for the Low CF scenario (namely $350 \%$ the volume of the carbonator). Assuming an average density of $1300 \mathrm{~kg} / \mathrm{m}^{3}$ for both hot and cold solids, the storage silos diameters are around $30 \mathrm{~m}$.

- Weekly cycling (Fig. 9.b): calciner line is designed at the PCPP weekly average load and the storage is large enough to store the excess of $\mathrm{CaCO}_{3}$-rich solids produced by the calciner during the weekend. The calciner line always works at its nominal load while the carbonator follows the PCPP operation. This solution requires a much higher dimension of the storage, with a total volume of about $79,600 \mathrm{~m}^{3}$ for the Medium CF scenario $(1055 \%$ the volume of the carbonator) and $110,970 \mathrm{~m}^{3}$ for the Low CF scenario $(1470 \%$ the volume of the carbonator). For these cases both vessels diameters are larger than $50 \mathrm{~m}$.

It must be highlighted that storage system of this size are commercially available for the storage of clinker in cement plants (Aumund, 2018). However, to author's knowledge, storing and handling of such amounts of solids at high temperature is not common in industrial practice and a dedicated engineering study is needed to assess the technical and economic feasibility of such large hot solids storage.

Table 12 shows the calculated capital costs for the PCPP and three PCPP + CaL plants. PCPP + CaL plants can benefit from the reduction of stack cost and the absence of FGD unit, moreover, they can exploit economies of scale for common equipment like coal, ash and sorbent handling, drying and crushing and the cost related to accessory electrical plant, instrumentation and control, building and structures and improvement to site. The first PCPP + CaL plant corresponds to the "Reference" case without solids storage presented in Section 2, with the carbonator and the calciner sized to treat the nominal flue gas mass flow rate of the given PCPP. The second PCPP + CaL plant has a calciner line with a size of $73.86 \%$ of the reference case. This value corresponds to the daily average capacity factor of the Medium CF operation profile presented in Section 4.1. TASC reduces by about $6.4 \%$ compared with the reference case, while the reduction of the specific capital cost is slightly lower (from $2631 € / \mathrm{kW}$ to $2481 € / \mathrm{kW}$, i.e. $-5.7 \%$ ), because of the small reduction of the nominal net power output. In fact, gross power output reduction is $-4.5 \%$ but the contextual reduction of both ASU and CPU consumptions leads to small variation of the net power output (from $1129.5 \mathrm{MW}$ to $1120.9 \mathrm{MW}$, i.e. $-0.73 \%$ ). The third PCPP + CaL plant has a calciner line size equal to $63.56 \%$ of the "Reference" case, corresponding to the daily average capacity factor of the Low CF profile presented in Section 4.1. Reduction of TASC by $9.15 \%$ and of specific capital cost by $8.23 \%$ was estimated for this case. Fig. 10 depicts the power balance at nominal conditions, the capital cost and the specific cost for the four systems.

\subsection{System optimization}

In this section, for the sake of brevity, mass and energy balances are discussed only for the Medium CF case, while economic results are reported for both medium and the low CF scenarios.

\subsubsection{Mass and energy balance}

Annual mass and energy balances are calculated by varying the size of the calciner line and the volume of the storage system. Results are graphically presented in Fig. 11 for the Medium CF operation profile presented in Section 4.1, for the cases with the carbonator designed on the PCPP full load gas flow rate. The size of the calciner line is varied between $60 \%$ and $100 \%$ of the reference case size, while the size of the solids storage system (i.e. sum of the volumes of the two silos) from $0 \%$ to $500 \%$ of the carbonator volume.

Fig. 11a shows the annual load of the carbonator, defined as the average mass flow rate of carbonated sorbent with respect to the nominal mass flow rate of the "Reference" case. For a calciner size equal to $100 \%$ the storage is not required and the carbonator always follows the PCPP load, leading to an average capacity factor equal to $67.5 \%$ over the 47 weeks of operation, namely equal to the weekly average value of PCPP operation referred to flue gases as reported in Table 9. Reducing the size of the calciner the maximum carbonator capacity factor can be reached only with a proper storage size (e.g. point A: calciner size equal to $90 \%$ of the reference value and overall storage volume equal to $95 \%$ of the carbonator volume). Smaller calciner sizes with the same storage volume (Line A) involve a reduction of the 


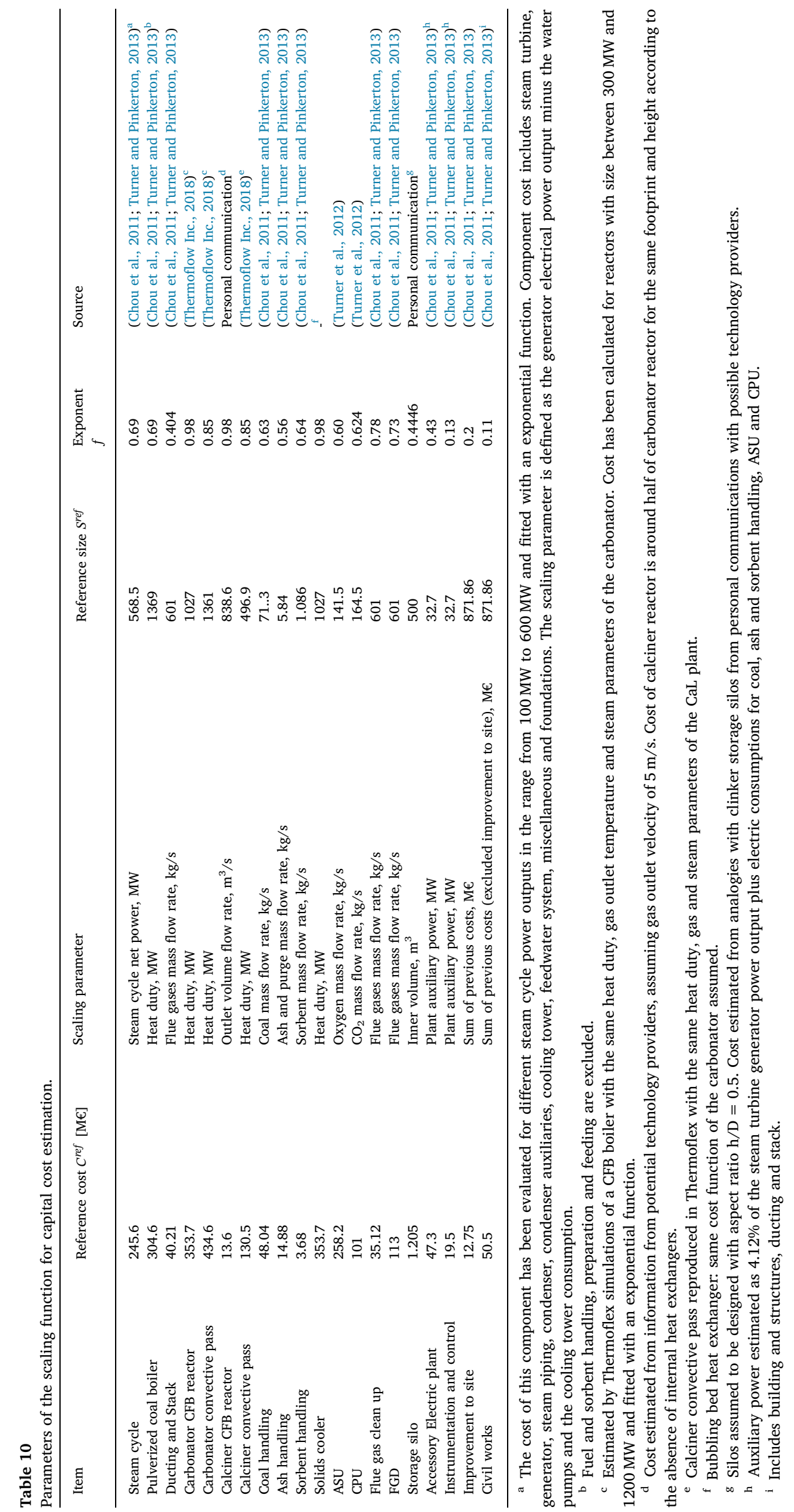


Table 11

Main assumptions for LCOE calculation.

\begin{tabular}{ll}
\hline Coal cost, $€ / \mathrm{t}$ & 65 \\
\hline Limestone cost, $€ / \mathrm{t}$ & 15 \\
Fixed Opex, $€ /$ TASC - year & 0.0258 \\
Variable Opex, €/MWh & 3.83 \\
$\mathrm{CO}_{2}$ transport and storage cost, $€ / \mathrm{t}$ & 7 \\
$\mathrm{CCF}$ & 0.11 \\
\hline
\end{tabular}

average carbonator load factor due to the lack of regenerated sorbent when the PCPP works at higher load (increased frequency of condition 2.b in Fig. 4), leading to an increase of $\mathrm{CO}_{2}$ emission (Fig. 11c). In order to limit $\mathrm{CO}_{2}$ emissions, it is always possible to define the minimum relative storage volume that allows to operate the carbonator independently from the calciner line (Line B). Reducing the size of the calciner, the needed storage volume increases linearly until the daily cycling condition is obtained (point B) (calciner size equal to $73.86 \%$ of the reference value and storage volume equal to $250 \%$ of carbonator volume). At this point a sharp change in the iso-load factor curves slope is highlighted (Line $C$ ) and motivated by the shift from a storage volume sized to manage the daily fluctuations, towards a larger storage system sized on the weekly production plan.

The average load of the calciner line (Fig. 11b) benefits from small size of the calciner and large storage systems. At the daily cycling sizing (Point B), the calciner relative load factor is equal to $90 \%$ due to the operation at low relative load $(70 \%)$ for a large part of the weekend (condition 1.a in Fig. 4). Higher values can be found only moving towards a weekly cycling with the storage system large enough to allow keeping a stable $100 \%$ relative load operation of the calciner during the whole week. In all the other cases the calciner operation is limited during part of the weekend since the storage tank fills up and the load of the calciner must be reduced to produce the exact amount of calcined sorbent needed in the carbonator (condition 1.a in Fig. 4). However, the advantages of coupling a smaller calcination line and a sufficiently large storage are evident, allowing to increase the calciner relative load factor from $67.5 \%$ of the reference case, up to more than $90 \%$ for the storage system sized on the daily cycling.

Fig. 11c depicts the annual $\mathrm{CO}_{2}$ emission. The minimum value of $480 \mathrm{t} / \mathrm{y}$ is found for storage volumes sufficiently large to fulfill the daily cycling requirement for any calciner size (points above line $B$ ). In these cases, the amount of $\mathrm{CO}_{2}$ released from the carbonator is around $65 \%$ of the total, while the remaining $35 \%$ is released from the CPU. For smaller storages the lack of CaO-rich solids during PCPP peak periods leads to a significant increase of $\mathrm{CO}_{2}$ emissions that becomes around twice as high as the minimum, for CaL system with small calciner line and no storage. In these cases, the $\mathrm{CO}_{2}$ released form the carbonator is around $80 \%$ of the total, the balance being the $\mathrm{CO}_{2}$ lost from the CPU.

Fig. 11d depicts the total annual net electric energy output of the CaLPP, which is function of both the heat available during the year and of the effects of the off-design operations. The maximum heat input

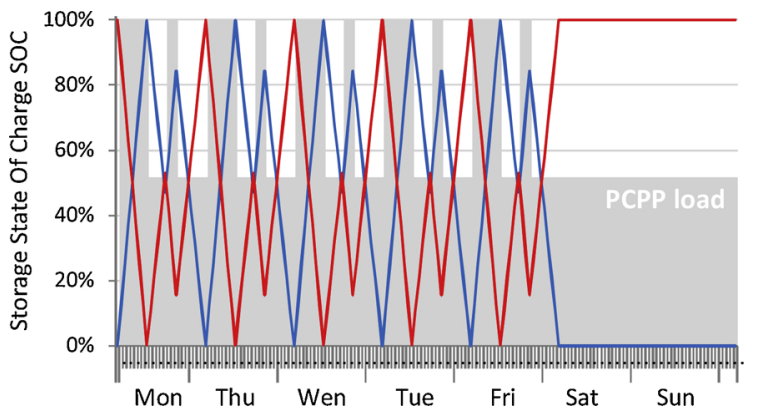

Table 12

Capital cost breakdown for the PCPP plant, for the reference PCPP + CaL plant without sorbent storage and for two PCPP + CaL plants with calcination line size equal to $74 \%$ and $64 \%$ of the reference one and storage system sized for daily cycling in the Medium $\mathrm{CF}$ and Low CF scenarios respectively.

\begin{tabular}{|c|c|c|c|c|}
\hline & PCPP & $\begin{array}{l}\mathrm{PCPP}+\mathrm{CaL} \\
\text { reference }\end{array}$ & $\begin{array}{l}\text { PCPP + CaL } \\
\text { Medium CF }\end{array}$ & $\begin{array}{l}\text { PCPP + CaL } \\
\text { Low CF }\end{array}$ \\
\hline Calciner line size factor & & $100 \%$ & $74 \%$ & $64 \%$ \\
\hline Storage relative volume & & & $250 \%$ & $350 \%$ \\
\hline Nominal Gross Power, MW & 804.8 & 1440.9 & 1375.6 & 1349.9 \\
\hline Nominal Net Power, MW & 747.2 & 1138.2 & 1129.9 & 1126.7 \\
\hline Nominal PB aux, MW & 33.13 & 59.32 & 56.63 & 55.57 \\
\hline Other Aux, MW & 24.49 & 50.68 & 46.72 & 45.16 \\
\hline ASU, MW & 0 & 70.61 & 52.15 & 44.88 \\
\hline CPU, MW & 0 & 122.11 & 90.19 & 77.61 \\
\hline PC steam cycle, M€ & 303.27 & 303.27 & 303.27 & 303.27 \\
\hline CaL steam cycle, $\mathrm{M} €$ & & 257.81 & 239.23 & 231.77 \\
\hline Pulverized coal boiler, M€ & 350.27 & 350.27 & 350.27 & 350.27 \\
\hline Ducting and stack, M€ & 43.83 & 40.11 & 40.11 & 40.11 \\
\hline Carbonator reactor, $\mathrm{M} €$ & - & 87.31 & 87.31 & 87.31 \\
\hline Carbonator convective pass, $\mathrm{M} €$ & - & 89.44 & 89.44 & 89.44 \\
\hline Calciner reactor, $\mathrm{M} €$ & - & 19.55 & 14.53 & 12.54 \\
\hline Calciner convective pass, M€ & - & 96.71 & 74.75 & 65.79 \\
\hline Coal handling, M€ & 46.01 & 66.85 & 61.82 & 59.76 \\
\hline Ash handling, M€ & 19.46 & 41.86 & 37.08 & 35.05 \\
\hline Sorbent handling, M€ & 3.53 & 35.84 & 29.70 & 27.08 \\
\hline HT solids cooler, M€ & - & 35.76 & 26.55 & 22.91 \\
\hline LT solids cooler, M€ & - & 102.26 & 102.26 & 102.26 \\
\hline ASU, M€ & - & 236.89 & 197.51 & 180.49 \\
\hline CPU, M€ & - & 144.53 & 119.62 & 108.93 \\
\hline Flue gas clean up, M€ & 41.47 & 34.95 & 34.95 & 34.95 \\
\hline FGD, M€ & 131.97 & - & - & - \\
\hline Storage system, M€ & - & - & 9.04 & 10.50 \\
\hline Accessory electrical plant, M€ & 60.40 & 123.27 & 112.68 & 108.13 \\
\hline Instrumentation and control, $\mathrm{M} €$ & 20.99 & 26.04 & 25.35 & 25.03 \\
\hline Improvement to site, $\mathrm{M} €$ & 13.16 & 15.19 & 14.98 & 14.89 \\
\hline Building and Structures, M€ & 51.38 & 55.41 & 55.01 & 54.83 \\
\hline TASC multiplier + owner cost, M€ & 417.01 & 830.89 & 777.94 & 754.85 \\
\hline TASC, M€ & 1502.7 & 2994.2 & 2803.4 & 2720.1 \\
\hline Specific capital cost, €/kW & 2011.1 & 2630.7 & 2481.2 & 2414.2 \\
\hline
\end{tabular}

during the year is found where the operation of both reactors is not limited by the storage size (points above line $B$ ). Outside of this region, the lower carbonator load factor results in a lower heat input to the CaLPP. Among the points with the maximum heat input, the higher power production is obtained for small calciner size, i.e. moving towards the weekly cycling sizing criteria. In fact, a smaller calciner involves a smaller nominal CaLPP power output but, if coupled with a sufficiently large storage, it can benefit from a lower off-design penalization, especially when the PCPP works at reduced load. However, moving from the daily cycling design towards the weekly cycling design (line $C$ ) results in a small increase of the energy output.

Fig. $11 \mathrm{e}$ depicts the yearly specific $\mathrm{CO}_{2}$ emission, which substantially reflects the carbonator load factor (Fig. 11a), the total $\mathrm{CO}_{2}$

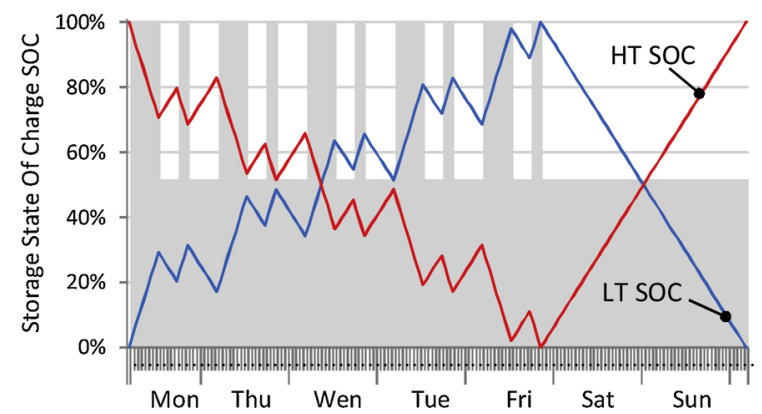

Fig. 9. High Temperature (HT) and Low Temperature (LT) storage State Of Charge (SOC) for systems designed for daily cycling (a) and weekly cycling (b) in the "Medium CF" scenario. 


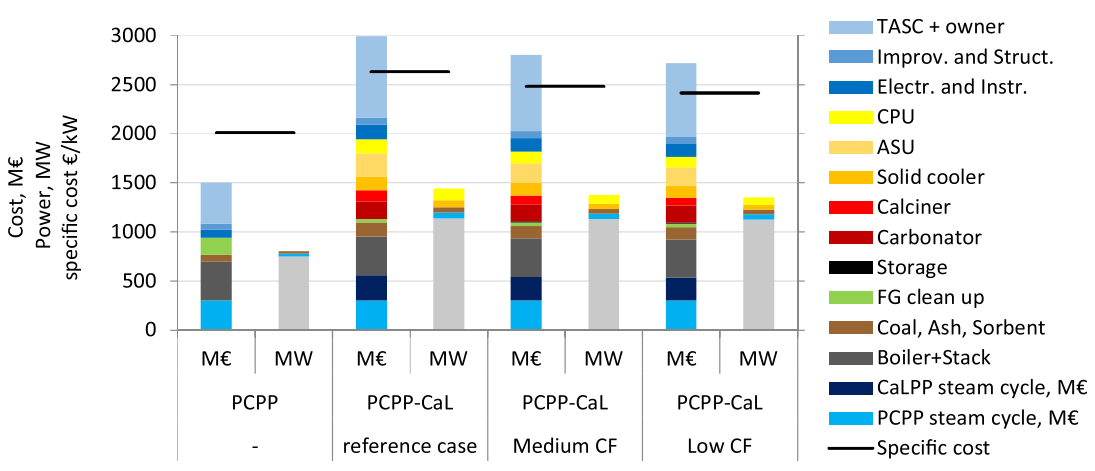

Fig. 10. - Breakdown of system capital cost, power balance and specific cost for the PCPP, for the "reference" CaL system and for two CaL system designed on the daily cycling for the Medium CF and Low CF scenarios.

emissions (Fig. 11c) and the additional energy output (Fig. 11d).

Finally, Fig. $11 \mathrm{f}$ shows the overall system efficiency calculated as the net energy produced by the PCPP + CaL system divided by the fuel input in both the PC boiler and the calciner. Efficiency slightly increases by reducing the calciner size and reducing the storage volume. These cases are characterized by a lower CCE and a lower amount of coal burned in the calciner, leading to a higher system efficiency. Finally, the yearly SPECCA index is reported in Fig. 12.

A similar trend for all the relevant quantities is obtained also for the Low CF scenario and daily cycling design (Point B) is correctly found for a calciner size equal to $63.56 \%$ of the reference case calciner and a storage overall volume equal to $350 \%$ the carbonator volume.

\subsubsection{Economic analysis}

Fig. 13 depicts the LCOE map for a case without carbon tax (Fig. 13a) for a case with $50 € / \mathrm{t}$ carbon tax (Fig. 13b) and for a case with $100 € / t$ carbon tax (Fig. 13c). The combination of calciner size and storage volume that minimizes the LCOE (red markers) changes depending on the carbon tax assumed: if no carbon tax is applied, the optimum design is found for the minimum calciner dimension and the maximum storage (in the investigated range) in order to minimize the capital cost related to calciner line and the cost due to carbon capture transportation and storage. For higher values of the carbon tax, the minimum LCOE design corresponds to the calciner size at maximum storage dimension (terminal point of Line $C$ ) since the very small cost of the storage makes always profitable moving towards the weekly cycling case where the calciner line size is minimized. However, the LCOE difference between the optimal point and the daily cycling case (Point $B$ ) is very small and sizing the storage system to manage the daily cycling, appears more reasonable for the logistical point of view. Considering Fig. 13b, all the cases above Line $B$ are penalized by a lower system efficiency and a lower CaLPP energy production due to off-design effects in part load operations (Fig. 11d). On the contrary, the increase of LCOE below Line $B$ is due to the increase of $\mathrm{CO}_{2}$ emission
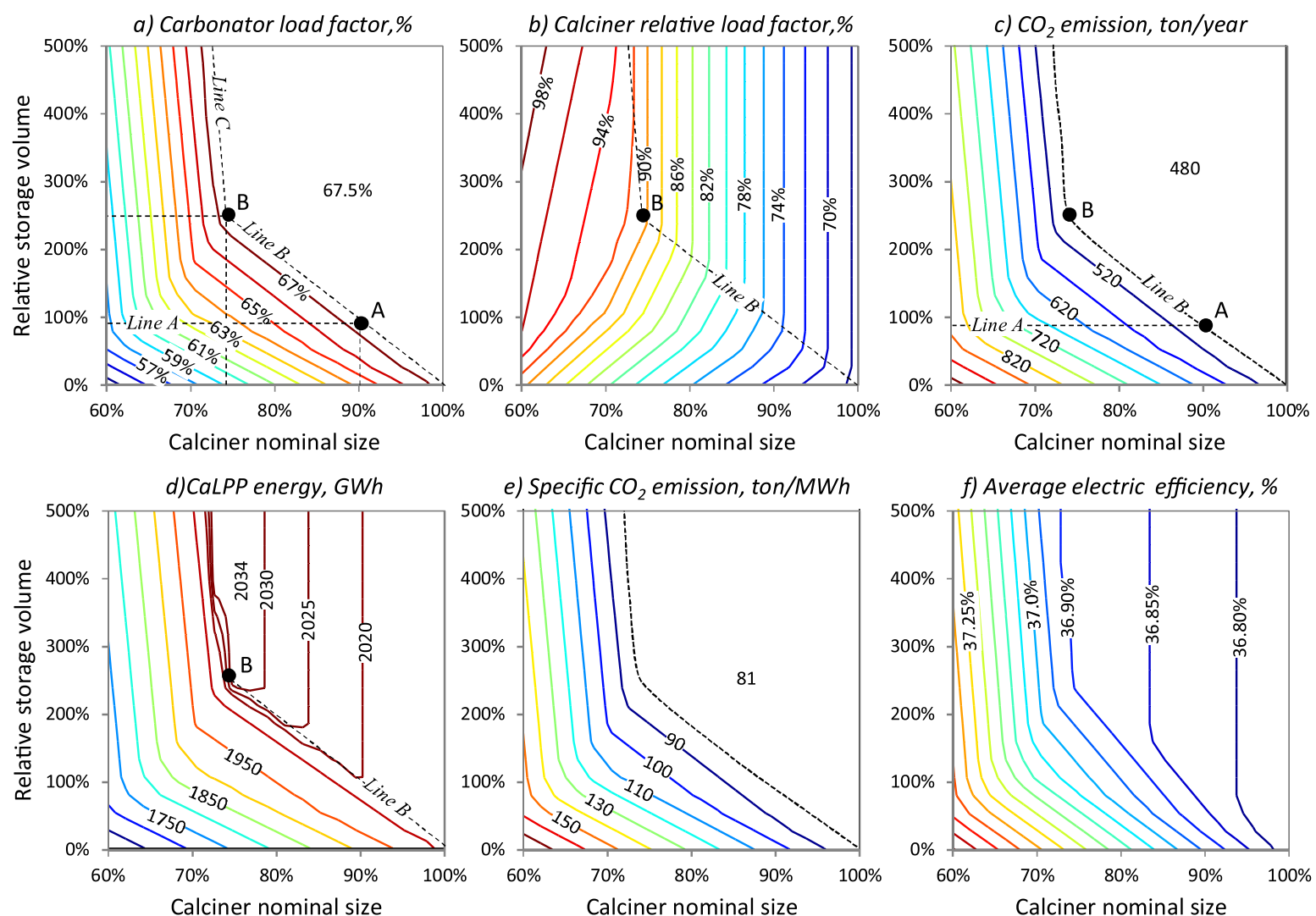

e) Specific $\mathrm{CO}_{2}$ emission, ton/MWh
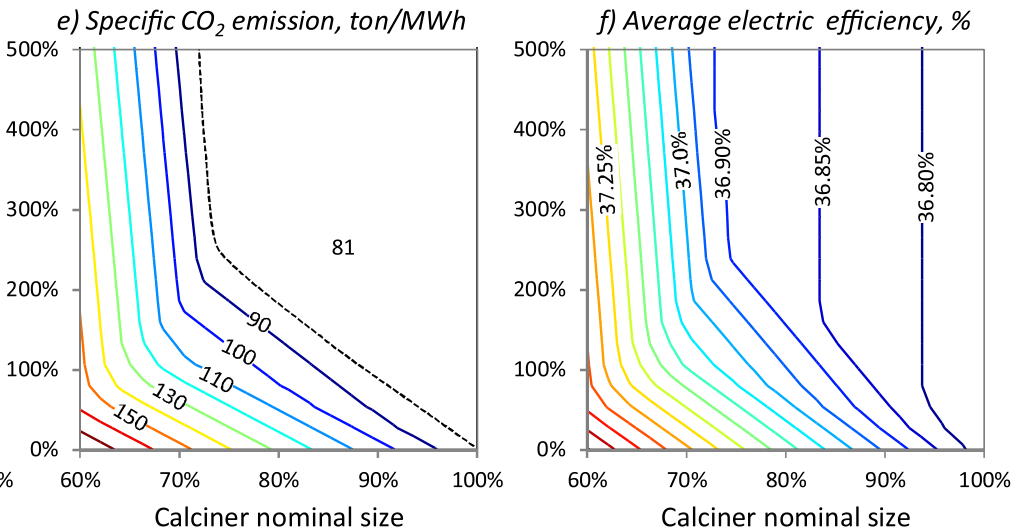

Fig. 11. Trend of significant quantities as function of the calciner size (\% with respect to the reference case) and the total storage volume of the two silos (\% with respect to the reference case carbonator volume). Carbonator size is always equal to the reference case one. 


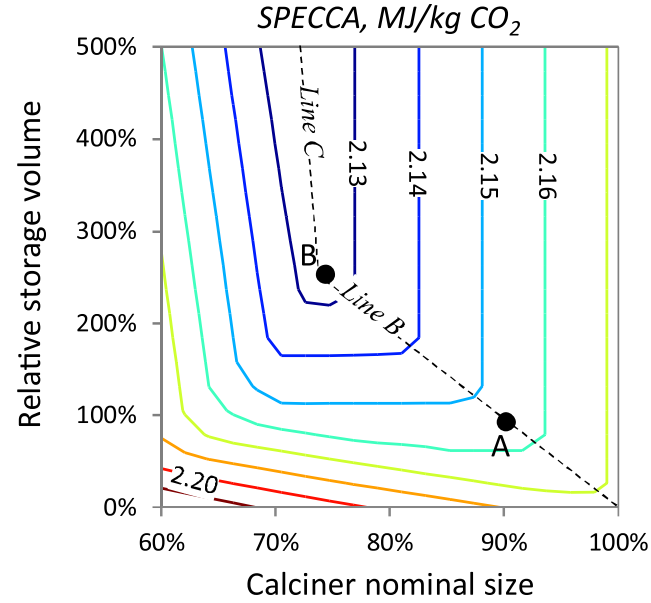

Fig. 12. SPECCA as function of the calciner size (\% with respect to the reference case) and the total storage volume of the two silos (\% with respect to the reference case carbonator volume). Carbonator size is equal to the reference case one.

and the associated emission cost. This second effect is more pronounced when the carbon tax increases to $100 € / \mathrm{t}$.

A similar result is found for the Low CF scenario (Fig. 14). The minimum value of LCOE is found again for a small calciner and the maximum storage volume but the optimal value is very similar to the LCOE of the case with daily cycling design.

On the whole, in the Medium CF scenario, a storage system sized for managing the daily cycling allows reducing the LCOE by $4.4 \%$ and $4.2 \%$ compared with the reference CaL system without storage, with a carbon tax of $50 € / \mathrm{t}$ and $100 € / \mathrm{t}$ respectively. In the Low CF scenario, the LCOE reduction obtained with the storage system is $6.8 \%$ and $6.6 \%$ with carbon tax of $50 € / \mathrm{t}$ and $100 € / \mathrm{t}$ respectively.

Fig. 15a refers to the Medium CF scenario and compares the LCOE of the PCPP, the LCOE of the reference case PCPP + CaL system and the LCOE of a PCPP + CaL with storage designed for daily cycling. The intersection between the PCPP and the PCPP + CaL curves defines the Cost of $\mathrm{CO}_{2}$ Avoided (CCA) that makes the two solutions equivalent from an economic standpoint. The proper optimization of the calciner and storage sizes allows to reduce the CCA from $40.72 € / t$ of the reference case to $34.15 € / t$ ( $-16 \%)$. Higher improvement is obtained for the Low CF scenario (Fig. 15b), where the adoption of the storage system leads to a CCA reduction from $46.35 € / t$ of the reference design to $34.55 € / \mathrm{t}(-25.5 \%)$.
Finally, Table 13 shows the LCOE breakdown for the Medium CF and the Low CF scenarios for the PCPP and the PCPP + CaL systems designed for daily cycling, with the breakeven carbon tax value. For the PCPP in the Medium CF scenario, the three main LCOE contributions are the Capex (40\%), the $\mathrm{CO}_{2}$ emission cost $(26 \%)$ and the coal cost (20\%). For the PCPP + CaL systems, the $\mathrm{CO}_{2}$ emission cost becomes a small fraction of the LCOE (3\%) while Capex and fuel cost increase ( $49 \%$ and $24 \%$ respectively) because of the loss in efficiency compared to a PCPP system and the cost of the additional $\mathrm{CO}_{2}$ capture plant equipment. For the Low $\mathrm{CF}$ scenario, the share of Capex increases further to $53 \%$ of the LCOE.

\section{Conclusions}

This work assessed a novel Calcium Looping system for the power sector with high temperature sorbent storage. The main outcomes of the study can be summarized as follows.

- The operating point of the CaL system (i.e. the load of the carbonator and the calciner line) is affected by the PC power plant (PCPP) load, the nominal size of the calciner line and the state of charge of the storage silos.

- Reducing the size of the calciner line always leads to a capital cost reduction, as the calciner line components (calciner, ASU and CPU) are significantly more expensive than silos for the storage of solids. The nominal net power output of the plant is slightly affected by the size of the calciner line, leading to a decrease of the specific plant cost when the size of the calciner line is reduced.

- The optimal CaL design can be found through a minimization of the LCOE, by varying both the size of the calciner and the volume of the storage system. With sufficiently high carbon tax, the minimum LCOE is obtained for a storage system sized on the weekly plant cycling, which results in very large (perhaps impractically large) silos. Sizing the storage system on the daily cycling leads to slightly higher LCOE, but more feasible silo design for a logistic viewpoint.

- With a storage system sized on the daily cycling and a carbon tax between $50 € / \mathrm{t}$ and $100 € / \mathrm{t}$, LCOE reduces by $4.4-4.2 \%$ and 6.8 $6.6 \%$ compared to the reference case without storage for the Medium CF (74\% on weekly basis) and the Low CF (64\% on weekly basis) scenarios respectively.

- With a storage system sized on the daily cycling, the breakeven carbon tax compared to the benchmark case without $\mathrm{CO}_{2}$ capture (i.e. the cost of $\mathrm{CO}_{2}$ avoided) reduces from 40.7 to $34.2 € / \mathrm{t}(-16 \%)$ and from 46.4 to $34.26 € / \mathrm{t}(-25.5 \%)$ in the Medium CF and the Low CF scenarios, respectively.
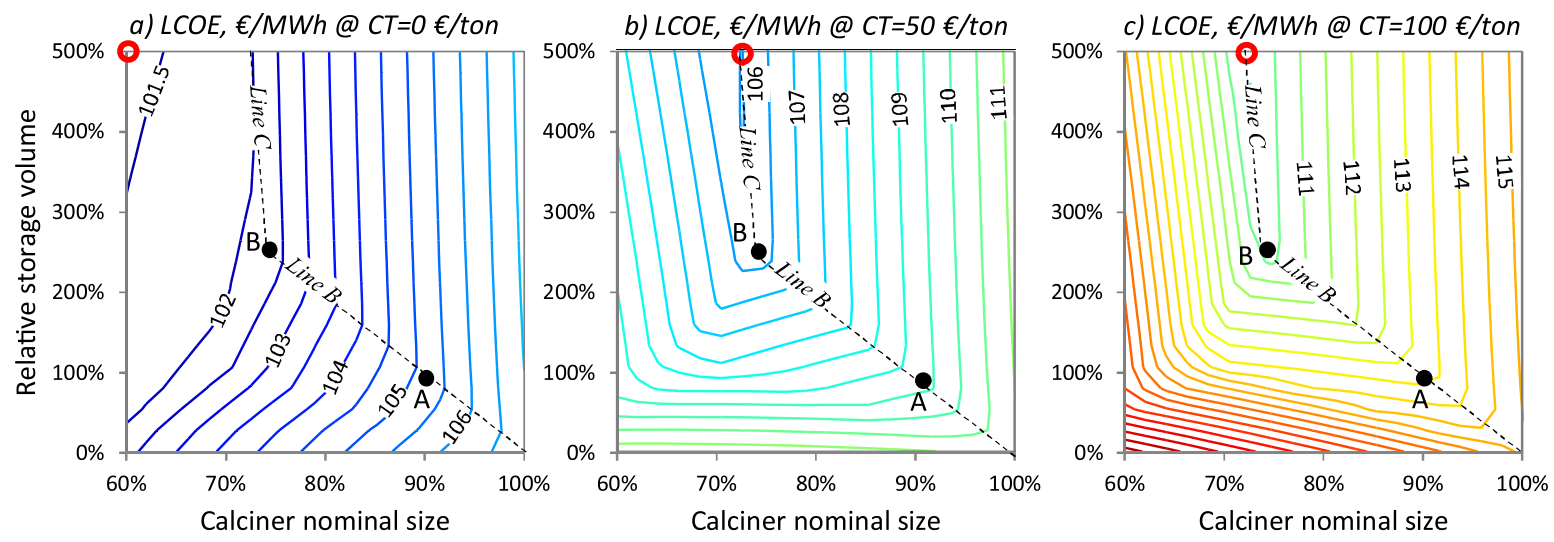

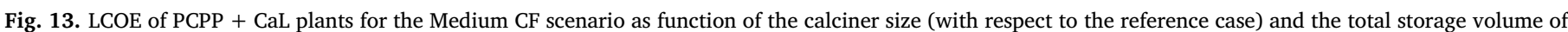

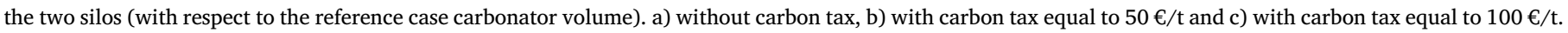



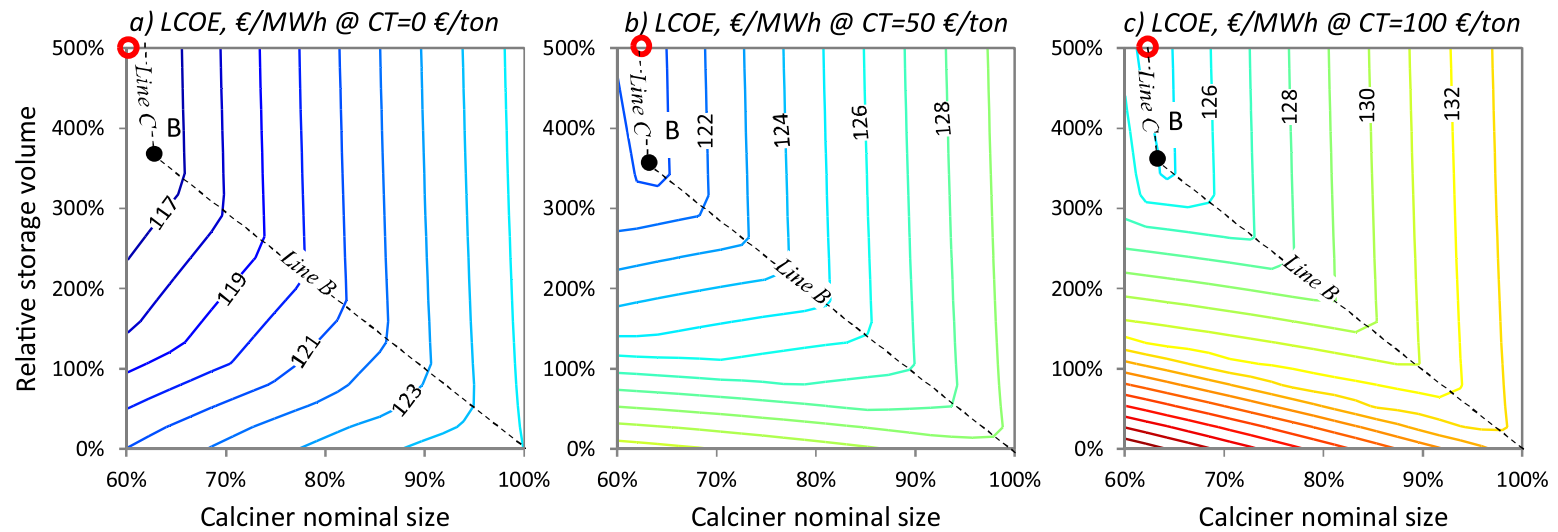

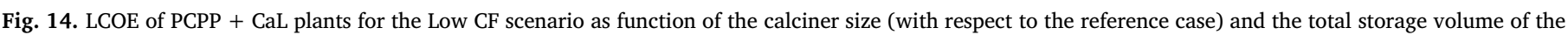

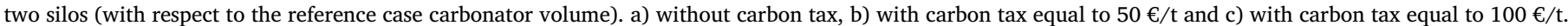

a) Medium CF scenario

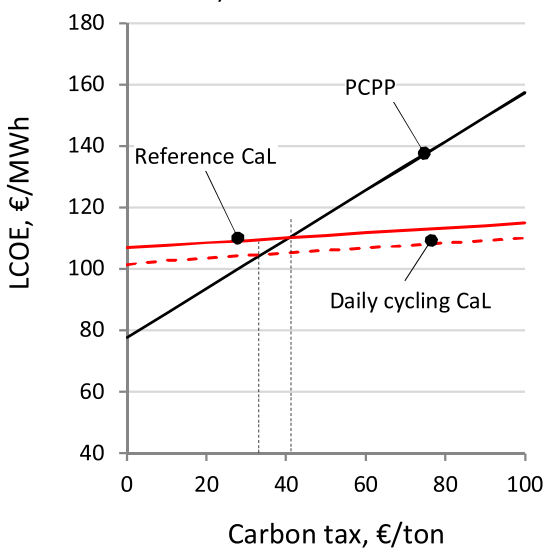

b) Low CF scenario

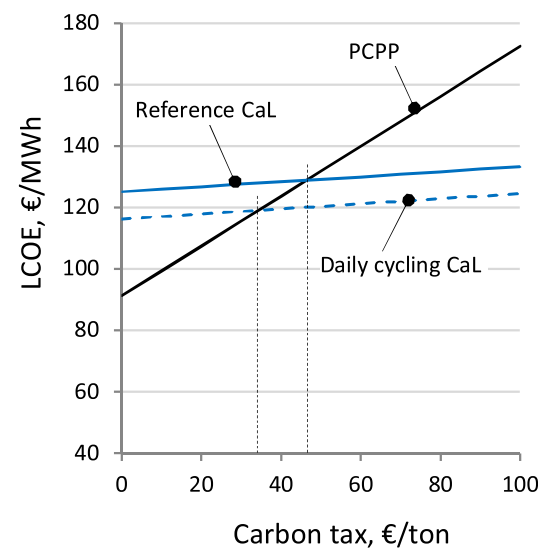

Fig. 15. LCOE vs. carbon tax for the PCPP, the reference CaL and the CaL system designed on the Daily Cycling for the Medium CF scenario (a) and for the Low CF scenario (b).

Table 13

LCOE breakdown for the PCPP and PCPP + CaL systems with daily cycling storage for Medium CF and Low CF scenarios with the breakeven carbon tax.

\begin{tabular}{|c|c|c|c|c|}
\hline & \multicolumn{2}{|c|}{ Medium CF scenario } & \multicolumn{2}{|c|}{ Low CF scenario } \\
\hline & PCPP & $\mathrm{PCPP}+\mathrm{CaL}$ & PCPP & $\mathrm{PCPP}+\mathrm{CaL}$ \\
\hline Carbon tax, $€ / \mathrm{t}$ & 34.15 & & 34.55 & \\
\hline Net electric energy output, GWh/year & 3910 & 5960 & 3117 & 4756 \\
\hline $\mathrm{CO}_{2}$ emission cost, $€ / \mathrm{MWh}$ & 27.23 & 2.75 & 28.01 & 2.82 \\
\hline Coal cost, €/MWh & 21.23 & 25.20 & 21.58 & 25.60 \\
\hline Limestone cost, $€ / \mathrm{MWh}$ & 0.07 & 1.79 & 0.08 & 1.81 \\
\hline Fixed Opex, €/MWh & 9.92 & 12.14 & 12.44 & 14.76 \\
\hline Variable Opex, €/MWh & 4.13 & 4.86 & 4.13 & 4.87 \\
\hline $\mathrm{CO}_{2}$ transport and storage, $€ / \mathrm{MWh}$ & 0.00 & 6.39 & 0.00 & 6.49 \\
\hline Capex, €/MWh & 42.28 & 51.74 & 53.03 & 62.92 \\
\hline LCOE, €/MWh & 104.9 & 104.9 & 119.3 & 119.3 \\
\hline
\end{tabular}

\section{Acknowledgements}

The project "FLexiCaL" leading to this study has received funding from the Research Fund for Coal and Steel under grant agreement No 709629.

\section{References}

Abanades, J.C., Arias, B., Lyngfelt, A., Mattisson, T., Wiley, D.E., Li, H., Ho, M.T., Mangano, E., Brandani, S., 2015. Emerging $\mathrm{CO}_{2}$ capture systems. Int. J. Greenh. Gas Control 40, 126-166. https://doi.org/10.1016/j.ijggc.2015.04.018.
Alonso, M., Cordero, J.M., Arias, B., Abanades, J.C., 2014. Sulfation rates of particles in calcium looping reactors. Chem. Eng. Technol. 37, 15-19. https://doi.org/10.1002/ ceat. 201200614.

Arias, B., 2016. An analysis of the operation of a flexible oxy-fired CFB power plant integrated with a thermal energy storage system. Int. J. Greenh. Gas Control 45, 172-180. https://doi.org/10.1016/J.IJGGC.2015.12.007.

Arias, B., Diego, M.E., Abanades, J.C., Lorenzo, M., Diaz, L., Martínez, D., Alvarez, J., Sánchez-Biezma, A., 2013. Demonstration of steady state $\mathrm{CO}_{2}$ capture in a $1.7 \mathrm{MW}_{\text {th }}$ calcium looping pilot. Int. J. Greenh. Gas Control 18, 237-245. https://doi.org/10. 1016/j.ijggc.2013.07.014.

Arias, B., Criado, Y.A., Sanchez-biezma, A., Abanades, J.C., 2014. Oxy-fired fluidized bed combustors with a flexible power output using circulating solids for thermal energy storage. Appl. Energy 132, 127-136. https://doi.org/10.1016/j.apenergy.2014.06. 074.

Arias, B., Alonso, M., Abanades, C., 2017. $\mathrm{CO}_{2}$ capture by calcium looping at relevant conditions for cement plants: experimental testing in a $30 \mathrm{~kW}$ th pilot plant. Ind. Eng. Chem. Res. 56, 2634-2640. https://doi.org/10.1021/acs.iecr.6b04617.

Arias, B., Diego, M.E., Méndez, A., Alonso, M., Abanades, J.C., 2018. Calcium looping performance under extreme oxy-fuel combustion conditions in the calciner. Fuel 222 711-717. https://doi.org/10.1016/J.FUEL.2018.02.163.

Aumund, 2018. Clinker Storage Systems. Accessed December 2018. www.aumund.de/ content/pdf/pageflip/102974506/clinker storage systems 150508.pdf.

Blamey, J., Anthony, E.J., Wang, J., Fennell, P.S., 2010. The calcium looping cycle for large-scale $\mathrm{CO}_{2}$ capture. Prog. Energy Combust. Sci. doi 36, 260-279. https://doi. org/10.1016/j.pecs.2009.10.001.

Chou, V.H., Haslbeck, J.L., Kyle, A., Kuehn, N.J., Lewis, E.G., Pinkerton, L.L., Shah, V., Varghese, E., Woods, M.C., Turner, M.J., 2011. Cost and Performance Baseline for Fossil Energy Plants. Volume 3b: Low Rank Coal to Electricity: Combustion Cases. DOE/NETL-2011/1463.

Criado, Y.A., Arias, B., Abanades, J.C., 2017. Calcium looping $\mathrm{CO}_{2}$ capture system for back-up power plants. Energy Environ. Sci. 10, 1994-2004. https://doi.org/10.1039/ c7ee01505d.

Criado, Y.A., Arias, B., Abanades, J.C., 2018. Effect of the carbonation temperature on the $\mathrm{CO}_{2}$ carrying capacity of CaO. Ind. Eng. Chem. Res. 57, 12595-12599. https://doi. org/10.1021/acs.iecr.8b02111.

De Lena, E., Spinelli, M., Martínez, I., Gatti, M., Scaccabarozzi, R., Cinti, G., Romano, M.C., 2017. Process integration study of tail-end Ca-Looping process for $\mathrm{CO}_{2}$ capture 
in cement plants. Int. J. Greenh. Gas Control 67, 71-92. https://doi.org/10.1016/j. ijggc.2017.10.005.

Dean, C.C., Blamey, J., Florin, N.H., Al-Jeboori, M.J., Fennell, P.S., 2011. The calcium looping cycle for $\mathrm{CO}_{2}$ capture from power generation, cement manufacture and hy drogen production. Chem. Eng. Res. Des. 89, 836-855. https://doi.org/10.1016/j. cherd.2010.10.013.

Diego, M.E., Arias, B., Méndez, A., Lorenzo, M., Díaz, L., Sánchez-Biezma, A., Abanades, J.C., 2016. Experimental testing of a sorbent reactivation process in La Pereda 1.7 $\mathrm{MW}_{\text {th }}$ calcium looping pilot plant. Int. J. Greenh. Gas Control 50, 14-22. https://doi. org/10.1016/J.IJGGC.2016.04.008.

Fan, C., Pei, D., He, X., Zhou, W., Wei, Z., 2017. A modified master cycle off-design performance and heat rate improvement optimization. American Society of Mechanical Engineers. Power Division (Publication) POWERhttps://doi.org/10. 1115/POWER-ICOPE2017-3063.

FlexiCaL, 2016. Development of Flexible Coal Power Plants with $\mathrm{CO}_{2}$ Capture by Calcium Looping. Research Fund for Coal and Steel (RFCS) project. www.flexical.eu.

Fout, T., Zoelle, A., Keairns, D., Turner, M., Woods, M., Kuehn, N., Shah, V., Chou, V., Pinkerton, L., 2015. Cost and Performance Baseline for Fossil Energy Plants Volume 1a: Bituminous Coal (PC) and Natural Gas to Electricity Revision 3. DOE/NETL2015/1723. .

GECOS, 2016. GS Software. www.gecos.polimi.it.

Grasa, G.S., Alonso, M., Abanades, J.C., 2008. Sulfation of CaO particles in a carbonation/ calcination loop to capture $\mathrm{CO}_{2}$. Ind. Eng. Chem. Res. 47, 1630-1635. https://doi. org/10.1021/ie070937+.

Hanak, D.P., Biliyok, C., Manovic, V., 2016. Calcium looping with inherent energy storage for decarbonisation of coal-fired power plant. Energy Environ. Sci. 9, 971-983. https://doi.org/10.1039/c5ee02950c.

Hilz, J., Helbig, M., Haaf, M., Daikeler, A., Ströhle, J., Epple, B., 2018. Investigation of the fuel influence on the carbonate looping process in 1 MWth scale. Fuel Process. Technol. 169, 170-177. https://doi.org/10.1016/J.FUPROC.2017.09.016.

Hogg, S., 2005. Admission conversion improves part load performance. Mod. Power Syst. 11-15.

Hornberger, M., Spörl, R., Scheffknecht, G., 2017. Calcium looping for $\mathrm{CO}_{2}$ capture in cement plants - pilot scale test. Energy Procedia 114, 6171-6174. https://doi.org/10. 1016/j.egypro.2017.03.1754.

IEA, 2010. Power Generation from Coal - Measuring and Reporting Efficiency Performance and $\mathrm{CO}_{2}$ Emissions.

Kremer, J., Galloy, A., Ströhle, J., Epple, B., 2013. Continuous $\mathrm{CO}_{2}$ capture in a 1-MWth carbonate looping pilot plant. Chem. Eng. Technol. 36, 1518-1524. https://doi.org/ 10.1002/ceat.201300084.

Leckner, B., Szentannai, P., Winter, F., 2011. Scale-up of fluidized-bed combustion - a review. Fuel 90, 2951-2964. https://doi.org/10.1016/j.fuel.2011.04.038.

Martínez, I., Murillo, R., Grasa, G., Rodríguez, N., Abanades, J.C., 2011. Conceptual design of a three fluidised beds combustion system capturing $\mathrm{CO}_{2}$ with $\mathrm{CaO}$. Int. J. Greenh. Gas Control 5, 498-504. https://doi.org/10.1016/J.IJGGC.2010.04.017.

Martínez, A., Lara, Y., Lisbona, P., Romeo, L.M., 2012. Energy penalty reduction in the calcium looping cycle. Int. J. Greenh. Gas Control 7, 74-81. https://doi.org/10.1016/ J.IJGGC.2011.12.005.

Martínez, I., Grasa, G., Parkkinen, J., Tynjälä, T., Hyppänen, T., Murillo, R., Romano, M.C., 2016. Review a nd research needs of Ca-Looping systems modelling for postcombustion $\mathrm{CO}_{2}$ capture applications. Int. J. Greenh. Gas Control 50, 271-304. https://doi.org/10.1016/j.ijggc.2016.04.002.

Matthews, L., Lipiński, W., 2012. Thermodynamic analysis of solar thermochemical $\mathrm{CO}_{2}$ capture via carbonation/calcination cycle with heat recovery. Energy 45, 900-907. https://doi.org/10.1016/J.ENERGY.2012.06.072.

Perejón, A., Romeo, L.M., Lara, Y., Lisbona, P., Martínez, A., Valverde, J.M., 2016. The Calcium-Looping technology for $\mathrm{CO}_{2}$ capture: on the important roles of energy integration and sorbent behavior. Appl. Energy 162, 787-807. https://doi.org/10. 1016/J.APENERGY.2015.10.121.

Reitz, M., Junk, M., Ströhle, J., Epple, B., 2016. Design and operation of a $300 \mathrm{~kW}_{\text {th }}$ indirectly heated carbonate looping pilot plant. Int. J. Greenh. Gas Control 54, 272-281. https://doi.org/10.1016/J.IJGGC.2016.09.016.

Romano, M.C., 2012. Modeling the carbonator of a Ca-looping process for $\mathrm{CO}_{2}$ capture from power plant flue gas. Chem. Eng. Sci. 69, 257-269. https://doi.org/10.1016/j. ces.2011.10.041.

Shimizu, T., Hirama, T., Hosoda, H., Kitano, K., Inagaki, M., Tejima, K., 1999. A twin fluid-bed reactor for removal of $\mathrm{CO}_{2}$ from combustion processes. Chem. Eng. Res. Des. 77, 62-68. https://doi.org/10.1205/026387699525882.

Spinelli, M., Martínez, I., Romano, M.C., 2018. One-dimensional model of entrained-flow carbonator for $\mathrm{CO}_{2}$ capture in cement kilns by Calcium looping process. Chem. Eng. Sci. 191, 100-114. https://doi.org/10.1016/j.ces.2018.06.051.

Spliethoff, H., 2010. Power Generation from Solid Fuels, Power Systems. Springer-Verlag, Berlin Heidelberg. https://doi.org/10.1007/978-3-642-02856-4.

Ströhle, J., Junk, M., Kremer, J., Galloy, A., Epple, B., 2014. Carbonate looping experiments in a $1 \mathrm{MW}_{\text {th }}$ pilot plant and model validation. Fuel 127, 13-22. https://doi. org/10.1016/j.fuel.2013.12.043.

Thermoflow Inc, 2018. Thermoflex v.27.0. www.thermoflow.com.

Turner, M.J., Pinkerton, L.L., 2013. Quality Guidelines for Energy System Studies: Capital Cost Scaling Methodology. Final Report DOE/NETL-341/013113.

Turner, M.J., Woods, M., Chen, S., Brasington, R.D., Haslbeck, J.L., Zhang, C., 2012. Advancing Oxycombustion Technology for Bituminous Coal Power Plants: An R\&D Guide. Final Report DOE/NETL-2010/1405.

Vorrias, I., Atsonios, K., Nikolopoulos, A., Nikolopoulos, N., Grammelis, P., Kakaras, E., 2013. Calcium looping for $\mathrm{CO}_{2}$ capture from a lignite fired power plant. Fuel 113, 826-836. https://doi.org/10.1016/J.FUEL.2012.12.087. 